\title{
Oryza nivara allele of a major effect QTL qFLA1.1 increases flag leaf area in rice
}

Haritha Guttikonda

ICAR - IIRR: Indian Institute of Rice Research

Gowthami Chandu

ICAR - IIRR: Indian Institute of Rice Research

Suchandranath Babu Munnam

ICAR - IIRR: Indian Institute of Rice Research

Kavitha Beerelli

ICAR - IIRR: Indian Institute of Rice Research

Divya Balakrishnan

ICAR - IIRR: Indian Institute of Rice Research

Madhusudhana Ragimasalawada

IIMR: ICAR-Indian Institute of Millets Research

N Sarla ( $\nabla$ sarla_neelamraju@yahoo.com )

Indian Institute of Rice Research https://orcid.org/0000-0002-0072-2172

\section{Research Article}

Keywords: Rice, Flag leaf area, Flag leaf size, Introgression line, Oryza nivara, QTL mapping

Posted Date: February 22nd, 2022

DOI: https://doi.org/10.21203/rs.3.rs-1353745/v1

License: (c) This work is licensed under a Creative Commons Attribution 4.0 International License. Read Full License 


\section{Abstract}

A stable back cross introgression line IL65 (IET22161) (Swarna/O. nivara $\mathrm{BC}_{2} \mathrm{~F}_{6}$ ) of rice was used to map flag leaf related traits in $\mathrm{F}_{2}$ and $\mathrm{F}_{3}$. A total of 12 QTLs were mapped for flag leaf related traits on two chromosomes with each QTL explaining 3 to $21 \%$ phenotypic variance (PV). Interestingly, a novel 12Mb QTL cluster (RM8094 - RM9) that controls 7 traits was identified on long arm of chromosome 1 where QTLs qSPAD1.2, qSPAD1.3 for SPAD, qFLL1.1, qFLL1.2 for flag leaf length, qFLW1.1, qFLW1.2 for flag leaf width, qFLA1.1, qFLA1.2 for flag leaf area, $q P H 1.1, q P H 1.2$ for plant height, qDTF1.2, qDTF1.3 for days to flowering and $q H I 1.2, q H 11.3$ for harvest index were co-located. Among these, one major effect QTL qFLA1.1 for flag leaf area was identified in a 9Mb region between RM8094 and RM5638. There was an adjacent minor effect QTL $q F L A 1.2$ in a 3Mb region between RM5638 and RM9. Together these two QTLs and with leaf area increasing QTL allele from 0. nivara explained $19.7 \%$ PV. The QTL for flag leaf related traits can be fine mapped and considered for breeding rice varieties with higher flag leaf area, photosynthetic rate and grain yield.

\section{Introduction}

Rice yield is the primary target trait in breeding programs. Conventional crop improvement methods have been found limiting in breaking current yield barriers. Molecular and biotechnological tools can complement the conventional methods to enhance rice yields. Earlier, ideotype breeding was described to improve plant architecture with short plant height, more tillers and panicles with erect flag leaves to enhance rice productivity (Wang and Li 2005). In recent years, improving canopy photosynthesis is recognized as a major avenue to enhance crop growth rate, biomass and grain yield (Song et al. 2016; Qu et al. 2017; Adachi et al. 2019; Chang et al. 2019). Enhancing photosynthesis at single leaf level is also an important factor to improve crop biomass (Makino 2011). Therefore, photosynthesis was turned out as one good target for breeders to look for lines with high net photosynthetic rate to develop high yielding lines (Teng et al. 2004). In our previous study we found that the introgression lines with high net photosynthetic rate showed high yield and total dry mass (Haritha et al. 2017, 2019). In cereals, the top three leaves, particularly flag leaf, is the most essential functional organ to produce a large proportion of photo-assimilates that are later stored in grains (Peng et al. 2008; Jiang et al. 2010; Sperotto et al. 2013; Sanchez-Bragado et al. 2016; Yin et al. 2017).

Flag leaf size and shape are important morphological determinants of plant architecture that affect photosynthesis to a certain extent and thus influence rice production (Tsukaya 2006; Yue et al. 2006; Zhang et al. 2015; Tang et al. 2018; Xie et al. 2019; Chen et al. 2019). It is estimated that it contributes around $32 \%$ of total carbohydrates during grain filling in rice, where as $41-43 \%$ in wheat (Sharma et al. 2003; Zheng et al. 2018). The larger the leaf size greater the efficiency of accumulation of photosynthates in seeds (Horton 2000; Wang et al. 2011; Wang et al. 2012). On the other hand, larger leaves often shadow lower leaves thus reducing radiation there by decreasing the leaf photosynthetic rate. Leaf size is a complex trait and the angle, thickness, folding, leaf temperature, leaf wax and several other traits need to be optimised in a canopy for maximum radiation use and efficiency. Even breeders consider the flag leaf size as a beneficial trait for sustaining yield potential in wheat under different water-deficit conditions (Isidro et al. 2012).

The plasticity of leaf size and shape are strongly dependent on environment conditions (Tsukaya et al. 2006). Asymmetric changes in day/night temperatures, light and air humidity show strong impact on plant growth rate, leaf area biomass and dry-matter (Stuerz and Asch 2019). High night temperature increases leaf growth including leaf area and photosynthesis (Jing et al. 2016). Leaf blade expansion is inhibited and petiole length enhanced during low light conditions in Arabidopsis (Kozuka et al. 2005). However, many studies show that these leaf morphological traits are significantly correlated with yield related traits. For example, flag leaf length was positively correlated with days to 50\% flowering (Marathi et al. 2012), panicle length (Marathi et al. 2012; Sonah et al. 2012; Rahman et al. 2013), plant height, tiller number (Sonah et al. 2012), grain number per panicle (Marathi et al. 2012), primary branch number, secondary branch number, panicle weight (Wang et al. 2012), 1000-grain weight, grain yield (Marathi et al. 2012, Zhang et al. 2015) and above ground biomass (Rahman et al. 2013; Eizenga et al. 2016). Similarly, flag leaf width was positively correlated with primary branch number, secondary branch number (Wang et al. 2012), spikelet number per panicle (Ding et al. 2011; Marathi et al. 2012), panicle weight (Wang et al. 2012) and yield per plant (Marathi et al. 2012; Zhang et al. 2015). The flag leaf area increases grain yield by increasing panicle length, number of primary branches, number of secondary branches, panicle length, panicle weight and spikelet number per panicle (Wang et al. 2012). Thus, leaf traits play a major role to enhance rice production (Yin et al. 2017; Fu et al. 2019; Dai et al. 2020).

Several QTLs were reported for flag leaf size and shape (flag leaf length, width, and area) using diverse mapping populations such as $F_{2}$, recombinant inbred lines (RILs), backcross recombinant inbred lines (BRILs), chromosome segment substitution lines (CSSLs) and doubled haploids (DH) in rice (Wang et al. 2004; Yue et al. 2006; Peng et al. 2007; Fan et al. 2007; Wang et al. 2012; Yang et al. 2018a; Dai et al. 2020; Wen et al. 2020), wheat (Liu et al. 2018a; Zhao et al. 2018a; Yan et al. 2020), maize (Zhao et al. 2018b) and barley (Liu et al. 2015; Alqudah et al. 2018). Kobayashi et al. (2003) identified nine genomic regions affecting flag leaf development in 190 RIL population derived from rice varieties Milyang23 and Ashikari. Among these, three chromosomal regions (group I) had stable QTLs that increased both FLL and FLW, whereas four regions (group II) had QTLs only for increasing FLL and other two regions (group III) had only QTLs for increasing FLW. Four QTLs were identified in four $F_{2}$ populations derived from IR64 and its introgression lines (IR64/new plant type rice) for flag leaf length and flag 
leaf width on chromosomes 1, 2 and 4. Among these qFLLnpt-4 at RM3843 and qFLWnpt-4 at RM17483 on chromosome 11 led to longer and wider flag leaves in IR64 introgression lines HFG39 population when allele was from YTK298 genome (Farooq et al. 2010). Sonah et al. (2012) identified a stable and major QTL qLL12.1 for flag leaf length between RM247 and RM6296 across 3 different climatic zones of India.

Similarly, Cai et al. (2015) identified 30 QTLs for flag leaf length, width and area in 2 DH populations of ZYQ8/JX17 and CJ06/TN1. Among these $q F L L-4 b$ for flag leaf length between RM252 and RM3276 on chromosome 4, $q L W$-12 for flag leaf width between G148 and RG413 on chromosome 12 and qFLA-2a for flag leaf area between CT87 and G1234 on chromosome 2 showed high PV and additive effects (26.3, 6.98), $(20.8,0.12)$ and $(13.8 \%, 3.41)$ respectively. Yang et al. $(2018 \mathrm{a})$ identified $25 \mathrm{QTLs}$ for flag leaf length and width in a DH population derived from japonica variety Maybelle and indica variety Baiyeqiu (BYQ). Yang et al. (2018b) identified 30 QTLs (15 in each) for flag leaf area under cold and drought stress condition from 2 RIL populations derived from Dongnong422 (DN422) x KY131 (Pop1) and Xiaobaijingzi (XBJZ) x KY131 (Pop 2). Recently, 24 QTLs for leaf morphology were identified in a RIL population derived from a cross between japonica cultivar Rekuangeng (RKG) and indica cultivar Taizhong1 (TN1). Among them 8 QTLs were detected for leaf length and 16 QTLs for leaf width on chromosome 1 (Wen et al. 2020). The lines used in these studies were developed from indica $\mathrm{x}$ indica, indica $\mathrm{x}$ japonica and japonica $\mathrm{x}$ japonica crosses. Flag leaf related QTLs have not yet been reported from wild species or their derivatives in rice. In all, 39 QTLs for flag leaf area have been reported using different mapping populations (www.gramene.org accessed on 20th November 2019).

Oryza is an agronomically important genus containing species with highly diverse morphological characteristics; however, the major genetic variations have not yet been fully exploited in rice breeding (Wambugu et al. 2013; Govindaraj et al. 2015; Haritha et al. 2016, 2018a). Therefore, wild species could be utilized as a potential source for further improvement in leaf structural and physiological traits which ultimately improve the efficiency of resource capture in modern cultivars equivalent to expected photosynthetic use efficiency in C4 rice. All these studies on FLL, FLW and FLA indicate that these traits are strongly related to grain yield. However, all previous QTL mapping studies for flag leaf were conducted in populations derived from intra-specific crosses of Oryza sativa. QTLs for flag leaf related traits have not been mapped previously using a wild species derived line as a parent. The aim of present study was to locate major QTLs for flag leaf related traits (flag leaf length, width and area) and its association with grain yield and related traits using simple sequence repeat markers.

\section{Materials And Methods}

Plant materials and development of mapping population

The experimental material consisted of $473 \mathrm{~F}_{2}$ plants and $427 \mathrm{~F}_{3}$ families derived from $\mathrm{F}_{1}$ between Swarna, a popular lowland elite indica rice cultivar used as a male parent and a stable elite introgression line RPBio4918-65S (IET22161) (hereafter referred as IL65) used as a female parent. IL65 was selected from $\mathrm{BC}_{2} \mathrm{~F}_{6}$ population of Swarna x O. nivara IRGC81848 developed by Swamy (2009). IL65 was a unique line and significantly differed from Swarna in several morphological, physiological and yield related traits. It was tall and non lodging, had long, wide, light green leaves, late duration, had well exserted semi compact panicle, and more number of filled grains per panicle (\%), possessing small slender and lighter colored seeds with acceptable grain quality compared to Swarna (Fig. 1). IL65 was entered in Initial Varietal Trial-Late (IVTL) and showed overall mean grain yield (4.39t/h) as much as National check Swarna (4.37t/h) in 2010 (AICRIP 2010, Haritha et al. 2018b). IL65 was also tolerant to prolonged shade (Panigrahy et al. 2018) and heat (Prasanth et al. 2017) and also showed high photosynthetic rate (Rao et al. 2018). The salient features of parents are given in Table S1 in Online Resource 2. Since, Swarna and IL65 have differences in many agro-morphological traits, culm and flag leaf anatomical analysis also performed at flowering stage. The scheme for development of mapping populations and confirmation of true $\mathrm{F}_{1} \mathrm{~s}$ using SSRs are shown in Fig. S1 in Online Resource 1.

Field evaluation of mapping population

The field trials were conducted at the experimental farm of Indian Institute of Rice Research (IIRR) (17区32' N and 78区40' E at altitude of 542.7 $\mathrm{m}$ above sea level), Hyderabad, during the wet season (June-December) of 2013 for $F_{2}$ and dry season (Jan-June) of 2014 for $F_{3}$ population along with two parents as checks. The mean monthly maximum temperature ranged from 26 to $33^{\circ} \mathrm{C}$ and average of $29.5^{\circ} \mathrm{C}$ in dry season. The mean monthly minimum temperature ranged from 12 to $23.6^{\circ} \mathrm{C}$ and average of $17.8^{\circ} \mathrm{C}$ in wet season. The mean monthly bright sunshine hours per day varied from 3.4 to $7.1 \mathrm{~h}$ with an average of $5.2 \mathrm{~h}$. During 2013 wet season total rainfall received was $703 \mathrm{~mm}$. The relative humidity in forenoon and afternoon fluctuated between 79.3 to $87.4 \%$ and 40.9 to $62.3 \%$, respectively during crop growing period.

The $473 \mathrm{~F}_{2}$ plants were evaluated under normal irrigated conditions as single seedlings representing each $\mathrm{F}_{2}$ in completely randomized design (CRD) with 21 plants in each row. Twenty-one day old plants were transplanted at uniform spacing of $15 \mathrm{~cm}$ between plants and $20 \mathrm{~cm}$ between rows. Only $427 \mathrm{~F}_{2}$ plants survived and observations on morphological and yield related traits were taken on each plant. The $427 \mathrm{~F}_{2}{ }^{-}$ derived- $F_{3}$ families were grown similarly under normal irrigated conditions in randomized block design (RBD) in 3 replications. Each family consisted of 30 plants planted in 3 rows of 10 plants each with a spacing of $15 \mathrm{~cm}$ between plants and $20 \mathrm{~cm}$ between rows. The data for yield and related traits were taken from middle 3 plants of middle row in each family and replicate. Standard agricultural practices were followed to raise the crop. 
Phenotyping

The quantitative data of 12 morphological and yield related traits were measured in $473 F_{2}$ plants and of 21 traits for three plants each of 427 $\mathrm{F}_{3}$ families in three replicates. Flag leaf size related traits were measured at heading stage and other yield related traits at maturity stage.

Measurement of flag leaf related traits

In $F_{2}$ single plant data were taken for all 12 traits, but in $F_{3}$ families the mean of middle three plants of centre row were taken from each replication. The relative content of leaf chlorophyll was measured by taking three SPAD measurements per flag leaf of middle three plants using Minolta 502 chlorophyll meter. Flag leaf length (FLL) was measured from leaf base to tip in 3 fully expanded flag leaves of main stem at heading and expressed in $\mathrm{cm}$. Flag leaf width (FLW) was measured at the middle of the flag leaf where it is widest at heading and expressed as cm. Flag leaf area (FLA) was calculated as FLA = FLL x FLW x A and expressed in $\mathrm{cm}^{2}$ (where A = 0.747, a constant value (Stickler et al. 1961). These 3 traits FLL, FLW and FLA determine the fag leaf size. Thickness $(\mathrm{mm})$ of 3 flag leaves from 3 plants was measured using vernier callipers.

Measurement of grain yield and yield related traits

Days to flowering (DTF) in $\mathrm{F}_{2}$ was determined by counting number of days taken from the day of sowing to first panicle emergence in each plant, and as days to $50 \%$ flowering (DFF) when 50 percent of the $F_{3}$ plants in a family flowered. $\mathrm{PH}$ (cm) was measured from the base of stem to tip of main panicle at maturity. Number of tillers (NT) and number of panicle bearing tillers/productive tillers (NPT) were counted manually at maturity. After harvesting grain yield (YLDP) was measured by taking the mean weight of dried (12-14\% moisture) grains from three plants of each replication and the mean yield was expressed in grams (g). Similarly, the weight of above ground biomass (BM) of three well dried plants (on which grain yield was taken) was measured and average was taken and expressed in grams (g). Total dry mass (TDM) was calculated as TDM = YLDP + BM. Similarly harvest index $(\mathrm{HI})$ was calculated as the ratio between YLDP and TDM of the plant and expressed in percentage $(\mathrm{HI}=\mathrm{YLDP} / \mathrm{TDM} \times 100)$. Panicle length $(\mathrm{PL})$ was measured from base (including peduncle length) to the tip of 3 panicles in each replication and expressed in $\mathrm{cm}$. Number of primary branches (NPB) and number of secondary branches per panicle whose length was measured was counted and average was taken. Number of filled grains per panicle (NFG), unfilled grains per panicle (UFG), total grains per panicle (GNP) including unfilled grains, was counted manually from 3 panicles of each replication. Spikelet fertility (SF) was calculated as ratio between NFG and GNP and expressed in percentage (SF = NFG/ GNP x 100). Panicle weight (PWT) of the main 3 panicles was measured and expressed in grams (g). Finally, 1000 grain weight (TGW) expressed in grams (g) was taken from 1000 randomly selected dried grains from each replication.

\section{Statistical analysis}

The mean data for each trait in $\mathrm{F}_{2}$ and three replications of $\mathrm{F}_{3}$ was subjected to statistical analysis. Analysis of variance (ANOVA) and multiple correlations were performed using STAR ver 2.0.1 (http://bbi.irri.org/products). Descriptive statistics and significance of variance components were determined using PB-Tools ver 1.4 (http://bbi.irri.org/products). Broad sense heritability was estimated using the method of Johanson et al. (1955) as heritability = [Genotypic variance/Phenotypic variance] $\times 100$ and expressed in percentage.

Genotyping of mapping population

The leaves of $427 \mathrm{~F}_{2}$ plants and parents were collected at 60 days old plant stage. Genomic DNA was isolated using a modified protocol of Zheng et al. (1995). The quality and quantity of DNA was measured through spectrophotometry using Nanodrop (ND 1000, Thermo Scientific, Madison, USA). DNA was diluted with TE (Tris EDTA) buffer to make the final concentration to 50ng/ $\mu$ l for PCR analysis. A total of 1609 RM (rice microsatellite) primers from all 12 chromosomes were used to survey the polymorphism between parents Swarna and IL65. The primers were chosen based on their genome-wide distribution and earlier reports (McCouch et al. 2002). It may be noted that IL65 is an introgression line $\left(\mathrm{BC}_{2} \mathrm{~F}_{6}\right)$ and genotypic data showed IL65 has loci which are either homozygous for Swarna (AA), or 0 . nivara (BB), or heterozygous loci $(A B)$ with alleles from both the parents. Only markers which were of different sizes and were homozygous in each parent [designated AA in Swarna and BB in IL65] were considered polymorphic for further segregation analysis in $\mathrm{F}_{2}$. Presence absence variation and non parental bands were not considered as polymorphic. Any marker polymorphic between Swarna and IL65 was assumed to be due to introgression from O. nivara IRGC81848 in IL65. Of these 110 markers were used to analyze marker segregation in $\mathrm{F}_{2}$ population.

The PCR reaction for simple sequence repeats (SSR) was performed in $10 \mu$ l reaction volume containing $50 \mathrm{ng}$ of template DNA, $0.2 \mu \mathrm{M}$ of each primer (both forward and reverse primers) and Emerald Amp PCR Master Mix (Takara Bio USA, Inc.). The PCR amplification was performed under the following conditions: initial denaturation at $94^{\circ} \mathrm{C}$ for $5 \mathrm{~min}$, followed by 35 cycles of denaturation at $94^{\circ} \mathrm{C}$ for $30 \mathrm{~s}$, annealing at $55^{\circ} \mathrm{C}$ 
for $30 \mathrm{~s}$, extension at $72^{\circ} \mathrm{C}$ for $1 \mathrm{~min}$, followed by the final extension at $72^{\circ} \mathrm{C}$ for $7 \mathrm{~min}$. Following amplification, the products were resolved on $3 \%$ agarose gel and bands were scored according to segregation of parental alleles in all samples for each of the primers separately.

Linkage map construction

A linkage map was constructed using the marker segregation data of 110 polymorphic simple sequence repeats (SSRs) in $427 \mathrm{~F}_{2}$ plants using Join map version 3.0 (Van Ooijen and Voorrips 2001). Within each linkage group the genetic distances were determined using Kosambi mapping function (Vinod 2011). Of the 110 SSRs used 17 markers were showing segregation distortion and dropped from linkage map construction; the remaining 93 SSRs were assigned to different linkage groups of 12 chromosomes based on the linkage map of Temnykh et al. (2001) (Fig. S2, Online Resource 1). The linkage groups were named according to Kim et al. (2005). A genome-wide LOD threshold ( $P<0.05)$ was fixed at 2.5 based on 1000 permutations for considering a QTL significant (Churchill and Doerge 1994).

QTL mapping

QTL mapping was carried out for mean values of each trait in $\mathrm{F}_{2}$ and $\mathrm{F}_{3}$ mapping populations using the software MapQTL version 5 (Van Ooijen 2006). The association between marker genotypes and trait values was determined using F-test in QTL cartographer 2.5. Interval mapping (IM) was carried out initially for the presence of a QTL for each position on the map (Lander and Botstein 1989). The marker closest to each of the QTL peaks was then selected as a co-factor and used in multiple-QTL mapping (MQM) [MQM = composite interval mapping (CIM)] following the backward elimination technique (Jansen and Stam 1994). The set of co-factors was adjusted if the most likely position of the QTL differed from that identified in the co-factor selection round, and subsequent rounds of MQM mapping were performed. Markers were removed as a co-factor if their LOD value dropped below the significance threshold. When LOD values in other regions reached a significant level, the MQM was repeated by adding new markers as co-factors until a stable LOD profile was reached. The confidence interval for each QTL was set at the 1-LOD support interval. This corresponds approximately to a probability of $<0.05$ for declaring false positives in the entire genome based on sparse-map model (Lander and Botstein 1989). Adjacent QTLs on the same chromosome were considered as different when the curve had a minimum between peaks that were at least 1-LOD unit below either peak or when the support intervals were non-overlapping (with at least $20 \mathrm{cM}$ ) (Lander and Botstein 1989). The LOD (logarithm of odds) value above 2.5 was considered for significant QTL detection. The position of the QTL was estimated as the point of maximum LOD value in the region under consideration. The phenotypic variance explained by a single QTL was calculated as the square of the partial correlation coefficient $\left(\mathrm{R}^{2}\right)$ with the observed variable, adjusted for cofactors. The additive effect of a putative QTL was estimated as half the difference between two homozygous classes.

Epistatic interactions between different marker loci were determined for all traits in $F_{2}$ and $F_{3}$ populations for single environment at a LOD of 5.0 using ICIM-EPI function in ICiMapping ver 4.1(Meng et al. 2015).

Identification of CSSLS

The genotypic data of 93 polymorphic markers in $427 \mathrm{~F}_{2}$ population was used in CSSL finder ver1.4 (http://mapdisto.free.fr/CSSLFinder/), to identify a minimal set of chromosome segment substitution lines (CSSLs) in Swarna background that represents the entire introgressions from O. nivara (i.e. derived from IL65).

Identification of putative candidate genes within the major QTL

The candidate genes were searched within the hotspot $1(12 \mathrm{Mb})$ that controls flag leaf size and yield related traits were determined by using gramene data base (http://www.gramene.org/) and RAP-DB (https://rapdb.dna.affrc.go.jp/).

\section{Results}

Phenotypic variations of parents

The phenotypic differences between Swarna and IL65 were significant for all traits, except for number of filled grains per panicle (NFG), intrinsic water use efficiency $\left(\mathrm{P}_{\mathrm{N}} / \mathrm{g}_{\mathrm{s}}\right)$ and ratio of chlorophyll a to chlorophyll b $(\mathrm{Chl} a / b)$. IL65 showed significantly higher flag leaf area, plant height, days to $50 \%$ flowering, biomass and total dry mass than Swarna (Fig. 1a, b, c, d, e, f, g). The mean, standard deviation, skewness and kurtosis for all traits are shown in Table S2 in Online Resource 2. Fifteen out of 33 traits were negatively skewed with values from - 1 to +1 . The kurtosis for all traits was negative except for yield per plant (YLDP), biomass (BM), spikelet fertility (SF), transpiration efficiency $\left(\mathrm{P}_{\mathrm{N}} / \mathrm{E}\right)$, chlorophyll b ( $\mathrm{Chl} \mathrm{b)} \mathrm{and} \mathrm{ratio} \mathrm{of} \mathrm{chlorophyll} a$ and $b(\mathrm{Chl} \mathrm{a/b})$ which showed positive kurtosis. The coefficient of variance (CV\%) values were highest for number of secondary branches per panicle (NSB) (CV = 29.03), followed by biomass (BM) (CV = 28.33), total number of grains per panicle $(T N G)(C V=28.07)$ and number of productive tillers per plant $(N P T)(C V=28.07)$. CV varied from 3.4 to $26.7 \%$ for the remaining traits. 
The transverse sections of culm showed more number of vascular bundles in IL65 (34) compared to Swarna (30) and large air spaces below epidermis only in Swarna absence in IL65 (Fig. 1h, i). Flag leaf showed filaments of cells found only in midrib of Swarna, absent in IL65 (Fig. 1j).

Phenotypic variations of $\mathrm{F}_{2: 3}$ populations

Transgressive segregants were observed for all traits in $F_{2}$ and $F_{3}$ (Fig. S3, Online Resource 1). Analysis of variance (ANOVA) showed significant $(P<0.01)$ variations for all traits in $\mathrm{F}_{3}$ population (Table 1). Most of the traits showed near normal distribution. But, flag leaf length, days to flowering, plant height and harvest index in $\mathrm{F}_{2}$, and flag leaf thickness, plant height, days to $50 \%$ flowering, spikelet fertility, panicle length, thousand grain weight and harvest index in $\mathrm{F}_{3}$ showed negative skewness (Fig. S4 and Fig. S5, Online Resource 1). Flag leaf length ranged from 11 to $40 \mathrm{~cm}$, flag leaf width from 0.5 to $5 \mathrm{~cm}$ and flag leaf area from 5.98 to $63.5 \mathrm{~cm}^{2}$. The coefficient of variation for flag leaf length, flag leaf width and flag leaf area ranged from 10.6 to 26.7 in $F_{2}$ and 18.5 to 30.8 in $F_{3}$. The $\mathrm{CV}$ was highest for yield per plant ( $64 \%$ in $\mathrm{F} 2$ and $52.4 \%$ in F3) and lowest for days to flowering ( $4.2 \%$ in $F_{2}$ and $4 \%$ in $F_{3}$ ). (Table S3 and Table S4, Online Resource 2 ).

Table 1

Analysis of variance of 21 traits in $\mathrm{F}_{3}$ population

\begin{tabular}{|c|c|c|c|c|c|c|c|c|c|}
\hline S. no & Variable & DF & Mean & SS & MS & Sum square error & Mean square error & F value & $\operatorname{Pr}(>F)$ \\
\hline 1 & SPAD & 428 & 37.27 & 30151.32 & 70.44 & 18179.87 & 8.49 & 8.29 & $0 \star \star \star *$ \\
\hline 2 & FLL & 428 & 23.84 & 26935.45 & 62.93 & 23060.28 & 10.77 & 5.84 & 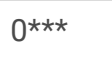 \\
\hline 3 & FLW & 428 & 1.24 & 94.21 & 0.22 & 106.24 & 0.05 & 4.43 & 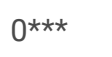 \\
\hline 4 & FLA & 428 & 22.16 & 61099.30 & 142.75 & 58992.63 & 27.56 & 5.18 & 0 *** \\
\hline 5 & FLT & 428 & 0.0745 & 0.18 & 0.00 & 0.26 & 0.00 & 3.42 & 0 *** \\
\hline 6 & $\mathrm{PH}$ & 428 & 107.16 & 996538.94 & 2328.36 & 127600.00 & 59.62 & 39.05 & 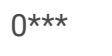 \\
\hline 7 & NT & 428 & 15.34 & 24108.47 & 56.32 & 31980.82 & 14.94 & 3.77 & $0 \star \star \star$ \\
\hline 8 & NPT & 428 & 15.04 & 23552.21 & 55.02 & 32167.09 & 15.03 & 3.66 & 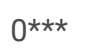 \\
\hline 9 & DFF & 428 & 126.55 & 91511.66 & 213.81 & 239.19 & 0.11 & 1912.93 & 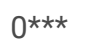 \\
\hline 10 & YLDP & 428 & 12.96 & 85847.45 & 200.57 & 33129.67 & 15.48 & 12.96 & 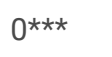 \\
\hline 11 & BM & 428 & 32.8 & 216556.93 & 505.97 & 119763.96 & 55.96 & 9.04 & 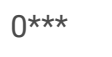 \\
\hline 12 & TDM & 428 & 45.75 & 431247.81 & 1007.58 & 162462.83 & 75.91 & 13.27 & $0 \star \star \star$ \\
\hline 13 & $\mathrm{HI}$ & 428 & 27.88 & 175096.71 & 409.10 & 122445.30 & 57.21 & 7.15 & $0 * \star \star$ \\
\hline 14 & $\mathrm{PL}$ & 428 & 21 & 11791.91 & 27.55 & 5260.92 & 2.45 & 11.21 & 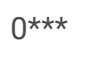 \\
\hline 15 & NPB & 428 & 10.04 & 3321.44 & 7.76 & 3768.66 & 1.76 & 4.41 & 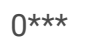 \\
\hline 16 & NSB & 428 & 26.78 & 148071.38 & 345.96 & 84332.80 & 39.40 & 8.78 & 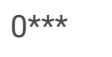 \\
\hline 17 & NFG & 428 & 113.7 & 2755200.65 & 6437.38 & 1275110.47 & 595.84 & 10.8 & 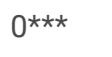 \\
\hline 18 & GNP & 428 & 137.45 & 2748886.77 & 6422.63 & 1394926.06 & 651.83 & 9.85 & 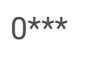 \\
\hline 19 & SF & 428 & 82.16 & 312853.66 & 730.96 & 169897.21 & 79.39 & 9.21 & 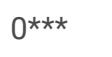 \\
\hline 20 & PWT & 428 & 1.72 & 714.43 & 1.66 & 255.82 & 0.12 & 13.96 & 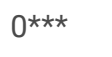 \\
\hline 21 & TGW & 428 & 15.02 & 6215.35 & 14.52 & 2211.69 & 1.03 & 14.05 & 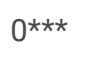 \\
\hline \multicolumn{10}{|c|}{ 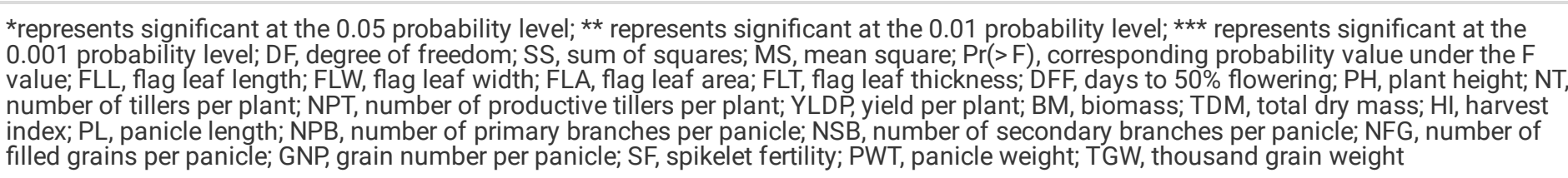 } \\
\hline
\end{tabular}

Correlation analysis

The Pearson's correlation coefficients between different flag leaf size and yield related traits showed a highly significant $(P<0.005)$ positive correlation between FLL and FLA in $\mathrm{F}_{2}$ (Table 2). In $\mathrm{F}_{3}$, FLL showed significant $(P<0.005)$ positive correlation with FLA, PH, BM, TDM and NSB 
whereas the correlation with FLW, NFG and NSB was significant at $P<0.01$ level, and with PL, NPB and YLDP was less significant $(P<0.05)$ compared with other traits (Table 3$)$. In addition, YLDP showed highly significant $(P<0.005)$ positive correlation with BM, TDM, HI, NSB, NFG, GNP, SF and PWT, but it was less significant for PL, NPB and TGW $(P<0.05)$. YLDP correlated significantly $(P<0.05)$ with FLL and FLA.

Table 2

Pearson's multi-trait correlation matrix for $F_{2}$ population

\begin{tabular}{|c|c|c|c|c|c|c|c|c|c|c|c|c|}
\hline Traits & SPAD & FLL & FLW & FLA & DTF & $\mathrm{PH}$ & NT & NPT & YLDP & BM & TDM & $\mathrm{HI}$ \\
\hline SPAD & 1.000 & & & & & & & & & & & \\
\hline FLL & 0.007 & 1.000 & & & & & & & & & & \\
\hline FLW & 0.051 & 0.140 & 1.000 & & & & & & & & & \\
\hline FLA & 0.032 & $0.657 * \star \star$ & $0.831^{\star \star *}$ & 1.000 & & & & & & & & \\
\hline DTF & 0.115 & -0.010 & 0.029 & 0.034 & 1.000 & & & & & & & \\
\hline $\mathrm{PH}$ & $-0.212^{\star}$ & 0.035 & -0.013 & 0.001 & -0.074 & 1.000 & & & & & & \\
\hline NT & 0.081 & 0.045 & -0.036 & 0.005 & 0.124 & 0.110 & 1.000 & & & & & \\
\hline NPT & 0.068 & 0.046 & -0.038 & 0.004 & 0.129 & 0.114 & $0.997 * \star \star$ & 1.000 & & & & \\
\hline YLDP & 0.087 & 0.131 & 0.002 & 0.073 & 0.032 & $0.268^{\star \star *}$ & $0.455^{\star \star \star}$ & $0.455^{\star \star \star}$ & 1.000 & & & \\
\hline BM & -0.023 & 0.100 & 0.066 & 0.108 & 0.109 & $0.296^{\star \star \star}$ & $0.457^{\star * \star}$ & $0.460^{\star \star *}$ & $0.647^{\star \star \star}$ & 1.000 & & \\
\hline TDM & 0.025 & 0.124 & 0.043 & 0.103 & 0.084 & $0.313^{\star \star *}$ & $0.501^{\star * *}$ & $0.503^{\star * *}$ & $0.873^{\star \star \star}$ & $0.937 * \star *$ & 1.000 & \\
\hline $\mathrm{HI}$ & 0.140 & 0.051 & -0.066 & -0.026 & 0.006 & 0.052 & 0.040 & 0.041 & $0.578 * \star \star$ & -0.091 & $0.207 *$ & 1.000 \\
\hline \multicolumn{13}{|c|}{$*, * *, * \star *$ represents significant at $0.05,0.01,0.005$ probability levels respectively } \\
\hline $\begin{array}{l}\text { FLL, } f \\
\text { produ }\end{array}$ & $\begin{array}{l}\text { eaf ler } \\
\text { e tillers }\end{array}$ & $\begin{array}{l}\text { FLW, fl } \\
\text { plant; } Y\end{array}$ & $\begin{array}{l}\text { eaf width } \\
\text {, yield pe }\end{array}$ & $\begin{array}{l}\text { A, flag } \\
\text { ant; BN }\end{array}$ & $\begin{array}{l}f \text { area } \\
\text { iomas }\end{array}$ & $\begin{array}{l}\text { F, days } t \\
\text { DM, tota }\end{array}$ & eading; $F$ & lant hei & NT, nun & of tillers & $\mathrm{T}, \mathrm{nu}$ & of \\
\hline
\end{tabular}

Broad sense heritability

The broad sense heritability $\left(\mathrm{H}^{2}\right)$ of all traits in $\mathrm{F}_{3}$ population ranged from $24.9 \%$ (number of productive panicles) to $100 \%$ (plant height). It was high (>60\%) for all traits, except in case of flag leaf width (22.78), leaf thickness (26.34), number of tillers (27.96) and number of productive panicles (24.94). It was moderate for flag leaf area (35.97), panicle weight (53.59) and thousand grain weight (48.63). The genetic advance (GA) as percent of mean was high (GA > 20\%) in four traits - days to $50 \%$ flowering, total dry mass, number of filled grains and grain number per panicle. The percentage of GA was moderate (10-20\%) for six traits, plant height, yield per plant, biomass, harvest index, secondary branches per panicle and spikelet fertility. GA value for other traits ranged from 0.16 to $10 \%$.

The phenotypic coefficient of variation (PCV\%) was higher than the corresponding genotypic coefficient of variation (GCV\%) for all traits. The GCV was high (25\%) for yield per plant, biomass, total dry mass, harvest index, number of secondary branches and number of filled grains per panicle (Table S5, Online Resource 2).

Pair-wise significance analysis of $\mathrm{F}_{3}$

Out of $427 \mathrm{~F}_{3}$ families 33 showed significantly $(P<0.05)$ higher values for one or more of 12 traits. Twelve families showed higher $\mathrm{PH}$ and only one IL367 showed higher PWT than both parents. Only 3 families IL1, IL353 and 457 showed significantly higher YLDP than both parents. However, 301 families out of 427 families had significantly lower values than both Swarna and IL65 (including 23 common families high for one trait and low for another) for 13 different traits (Table S6, Online Resource 2). 253 families showed significantly lower YLDP than both parents (Fig. S6, Online Resource 1).

\section{Marker segregation}

Of the 1609 simple sequence repeats (SSR) used 142 showed polymorphism between parents Swarna and IL65 (Table S7, Online Resource 2). Introgression of 110 polymorphic loci was analyzed in $427 \mathrm{~F}_{2}$ plants. Introgression percentage varied from chromosome to chromosome (Fig. S7, Online Resource 1). Only $0.23 \%$ (IL414) plants were homozygous for 0 . nivara alleles and showed maximum $97.2 \%$ introgression of homozygous 0 . nivara except for RM31 on chromosome 5, RM20917 on chromosome 7 and RM224 on chromosome 11 which were heterozygous at this locus. Similarly, 0.23\% (IL37) plants were homozygous for Swarna at all loci (98.1\%) except for RM19391 on chromosome 
6 and RM1235 on chromosome 8 . Likewise, $0.23 \%$ of plants (IL123) were heterozygous for maximum $78.1 \%$ loci except for 24 loci. The overall introgression of $O$. nivara alleles in $427 \mathrm{~F}_{2}$ plants ranged from 1.8 to $97.2 \%$ with an overall mean introgression of $24 \%$ compared to the expected introgression of $25 \%$.

Marker- trait associations

A total of 109 marker-trait associations were identified significantly $(P<0.001)$ for 12 morphological and yield related traits in $F_{2}$. Of these, 3 markers RM8094 associated with FLW, FLA and HI, RM5638 with FLW, DTF and HI and RM9 with FLW and DTF on chromosome 1. Likewise, RM3274, RM7485 on chromosome 2 were significantly $(P<0.05)$ associated with 5 (SPAD, NT, NPT, YLDP and TDM) yield related traits (Table S8, Online Resource 2). Similarly, 216 significant marker-trait associations were identified for 21 traits in $F_{3}$ population. Of these RM5638, RM9 and RM3642 on chromosome 1 were significantly $(P<0.001)$ associated with FLL, FLW, FLA, PH and HI. Similarly, RM10167, RM3652 and RM84 were significantly $(P<0.05)$ associated with 11 traits (SPAD, PH, YLDP, TDM, HI, PL, NPB, NSB, NFG, GNP and PWT) on chromosome 1 (Table S9, Online Resource 2).

QTL analysis

A total of 32 QTLs were identified on 8 chromosomes $\left(1,2,3,5,6,7,10\right.$, and 12) in $\mathrm{F}_{2}$. Of these, maximum 22 (68.7\%) QTLs had trait-enhancing alleles from Swarna and only 10 (31.2\%) had trait-enhancing alleles from IL65. The QTLs accounted for 2.5 to $13.5 \%$ of the phenotypic variation (PV) individually for the trait with LOD ranging from 2.5 to 9.7. In $F_{3}, 29$ QTLs were identified on 6 chromosomes (1, 2, 3, 5, 7, 12). Of these, maximum 21 (72.4\%) QTLs had trait enhancing alleles from IL65 (i.e.O. nivara allele) and 8 (27.5\%) trait enhancing QTL alleles were from Swarna. The PV ranged from 2.5 to $21 \%$ and LOD from 2.5 to 9.9 (Fig. 2a).

QTLs for flag leaf size related traits

In $\mathrm{F}_{2}$, Three QTLs $q F L W 1.1$, qFLW1.2 and $q F L W 1.3$ on chromosome 1 and one QTL $q F L W 8.1$ on chromosome 8 were detected for flag leaf width. On chromosome 1 the trait enhancing QTL allele was from IL65, whereas on chromosome 8 it was from Swarna. Each QTL explained 3.4 to $8.1 \%$ of PV. In $\mathrm{F}_{3}$, two QTLs $q F L L 1.1$ and qFLL1.2 for flag leaf length were identified adjacent to each other on chromosome 1 , and the trait enhancing QTL allele was from IL65. These two QTLs together explained 17.7\% of the total PV. Likewise, two QTLs qFLW1.1 and $q F L W 1.2$ for flag leaf width were detected on chromosome 1 and explained 4.3 and 13.6\% PV at a LOD score of 3.7 and 5.1 respectively. Interestingly, these two QTLs are common across two generations within the same genomic region on chromosome 1 (RM8094 - RM5638 and RM5638 $\mathrm{RM9}$ ) in both $\mathrm{F}_{2}$ and $\mathrm{F}_{3}$ (Table 4). Four QTLs qFLA1.1, qFLA1.2 on chromosome 1 and qFLA12.1, qFLA12.2 on chromosome 12 for flag leaf area were detected in $\mathrm{F}_{3}$. The trait enhancing QTL allele in all 4 QTLs were from 0 . nivara and explained 3-21\% PV. 
Table 4

QTLs detected for flag leaf size in $F_{2}$ and $F_{3}$ populations. Common QTLs in $F_{2}$ and $F_{3}$ are in blue. Major QTL in $F_{3}$ is in bold

\begin{tabular}{|c|c|c|c|c|c|c|c|c|c|c|c|c|c|}
\hline \multirow[t]{2}{*}{ Trait } & \multirow[t]{2}{*}{ Chr } & \multirow{2}{*}{$\begin{array}{l}\text { Marker } \\
\text { interval }\end{array}$} & \multirow{2}{*}{$\begin{array}{l}\text { Allelic } \\
\text { effect }\end{array}$} & \multicolumn{5}{|l|}{$\mathrm{IM}$} & \multicolumn{5}{|l|}{ CIM } \\
\hline & & & & LOD & $\mathbf{R}^{2}$ & Additive & Dom & $\begin{array}{l}\text { Peak } \\
\text { position }\end{array}$ & LOD & $\mathrm{R}^{2}$ & Additive & Dom & Peak \\
\hline
\end{tabular}

\section{Position \\ F3-flag leaf \\ length}

\begin{tabular}{lllllllllllll} 
qFLL1.1 & 1 & $\begin{array}{l}\text { RM8094- } \\
\text { RM5638 }\end{array}$ & $\begin{array}{l}\text { O. } \\
\text { nivara }\end{array}$ & 5.7 & 12.6 & -1.5 & -1.68 & 87.95 & - & - & - & - \\
\hline qFLL1.2 & 1 & $\begin{array}{l}\text { RM5638- } \\
\text { RM9 }\end{array}$ & $\begin{array}{l}\text { O. } \\
\text { nivara }\end{array}$ & 4.8 & 5.1 & -1.02 & -0.54 & 109.93 & 4.8 & 5.1 & -1.03 & -0.54 \\
\hline
\end{tabular}

\section{F3-flag leaf}

width

\begin{tabular}{|c|c|c|c|c|c|c|c|c|c|c|c|c|c|}
\hline$q F L W 1.1$ & 1 & $\begin{array}{l}\text { RM8094- } \\
\text { RM5638 }\end{array}$ & $\begin{array}{l}\text { O. } \\
\text { nivara }\end{array}$ & 5.1 & 13.6 & -0.08 & -0.09 & 84.95 & - & - & - & - & - \\
\hline$q F L W 1.2$ & 1 & $\begin{array}{l}\text { RM5638- } \\
\text { RM9 }\end{array}$ & $\begin{array}{l}\text { O. } \\
\text { nivara }\end{array}$ & 3.7 & 4.3 & -0.04 & -0.05 & 105.93 & 3.7 & 4.3 & -0.04 & -0.05 & 105.93 \\
\hline
\end{tabular}

\section{F2- flag \\ leaf width}

\begin{tabular}{|c|c|c|c|c|c|c|c|c|c|c|c|c|c|}
\hline$q F L W 1.1$ & 1 & $\begin{array}{l}\text { RM1- } \\
\text { RM8052 }\end{array}$ & $\begin{array}{l}O . \\
\text { nivara }\end{array}$ & 2.6 & 4.2 & -0.08 & -0.04 & 43.17 & - & - & - & - & - \\
\hline$q F L W 1.2$ & 1 & $\begin{array}{l}\text { RM8094- } \\
\text { RM5638 }\end{array}$ & $\begin{array}{l}\text { O. } \\
\text { nivara }\end{array}$ & 4.6 & 7.2 & -0.09 & 0.02 & 81.95 & 5.2 & 8.1 & -0.1 & 0.02 & 82.95 \\
\hline$q F L W 1.3$ & 1 & $\begin{array}{l}\text { RM5638- } \\
\text { RM9 }\end{array}$ & $\begin{array}{l}\text { O. } \\
\text { nivara }\end{array}$ & 3.7 & 4.3 & -0.04 & -0.05 & 105.93 & - & - & - & - & - \\
\hline$q F L W 8.1$ & 8 & $\begin{array}{l}\text { RM3845- } \\
\text { RM7356 }\end{array}$ & Swarna & - & - & - & - & - & 2.5 & 3.4 & 0.07 & -0.02 & 14 \\
\hline
\end{tabular}

\section{F3-flag leaf \\ area}

\begin{tabular}{|c|c|c|c|c|c|c|c|c|c|c|c|c|c|}
\hline qFLA1.1 & 1 & $\begin{array}{l}\text { RM8094- } \\
\text { RM5638 }\end{array}$ & $\begin{array}{l}\text { O. } \\
\text { nivara }\end{array}$ & 9.9 & 21 & -2.74 & -3.04 & 87.95 & 3 & 12.7 & -2.45 & -2.9 & 87.95 \\
\hline$q F L A 1.2$ & 1 & $\begin{array}{l}\text { RM5638- } \\
\text { RM9 }\end{array}$ & $\begin{array}{l}\text { O. } \\
\text { nivara }\end{array}$ & 7.3 & 8 & -1.73 & -1.33 & 104.93 & 6.4 & 7 & -1.66 & -1.28 & 104.93 \\
\hline$q F L A 12.1$ & 12 & $\begin{array}{l}\text { RM27970- } \\
\text { RM235 }\end{array}$ & $\begin{array}{l}\text { O. } \\
\text { nivara }\end{array}$ & 3.7 & 6 & -1.27 & -1.07 & 17 & - & - & - & - & - \\
\hline$q F L A 12.2$ & 12 & $\begin{array}{l}\text { RM235- } \\
\text { RM5479 }\end{array}$ & $\begin{array}{l}\text { O. } \\
\text { nivara }\end{array}$ & 3.2 & 5.2 & -1.3 & -0.88 & 34.76 & - & - & - & - & - \\
\hline
\end{tabular}

Chr- denotes chromosome; LOD, logarithm of odds; $\mathrm{R}^{2}$, percentage of phenotypic variation explained by the QTL; Additive, additive effect of the QTL (positive value indicates additive effect is from Swarna and negative additive value indicates additive effect is from IL65 ( 0 . nivara IRGC81848)), Dom, dominance effect of the QTL

QTLs for yield related traits

In $\mathrm{F}_{3}$, three QTLs were detected for SPAD on chromosome 1. The trait enhancing allele for qSPAD1. 1 was from Swarna with a LOD of 4.4 and explained 5.2\% of PV. The trait enhancing alleles for other two QTL qSPAD1.2 and qSPAD1.3 were from 0 . nivara and contributed 4.8 and 3\% PV respectively. The effects of these QTLs were of either partial dominance or additive in nature.

In all 10 QTLs were detected for days to flowering on 5 chromosomes $\left(1,3,6,10\right.$, and 12) in $\mathrm{F}_{2}$. Of these only two QTLs qDTF1.1 and qDTF3.1 had trait enhancing QTL alleles from 0 . nivara and remaining trait enhancing alleles were from Swarna and explained PV ranging from 4.2 to 13.5\%. One major QTL qDTF1.2 contributed by Swarna explained $13.5 \%$ of PV with a LOD value of 6.7 . It increases the flowering time by 2 days but 0 . nivara allele lowers flowering time. Three QTLs qNT2.1, qNT2.2 and qNT2.3 for tiller number were identified on chromosome 2. All the trait enhancing QTL alleles were from Swarna and explained PV of 4.3, 5.5 and 4.5\% respectively. Similarly, four QTLs for productive tiller number were detected on two chromosomes (2, and 12). Three of these QTLs qNPT2.1, qNPT2.2 and qNPT2.3 had trait enhancing alleles from 
Swarna as in the case of NT QTLs and they contributed PV ranging from 3.4 to $5.4 \%$ (Table S10, Online Resource 2). O. nivara allele was trait enhancing in only one QTL qNPT12.1

In $\mathrm{F}_{2}$, three QTLs $q Y L D P 2.1, q Y L D P 2.2$, qYLDP5.1 for yield per plant were detected on two chromosomes (2 and 5). Two of these traits enhancing QTL alleles on chromosome 2 were from Swarna and one QTL allele on chromosome 5 was from 0 . nivara. Of these, $q Y L D P 2.2$ explained high PV of 6.6\%. In $\mathrm{F}_{3}$, two QTLs $q Y L D P 1.1$ and $q Y L D P 1.2$ were detected on chromosome 1 and in both the trait enhancing QTL alleles were from 0 . nivara.

Four QTLs were detected on three chromosomes (1, 2 and 5) for biomass in $\mathrm{F}_{2}$. Trait enhancing alleles in two QTLs ( $q B M 1.1$ and $\left.q B M 5.1\right)$ were from 0. nivara and in two (qBM2.1 and qBM2.2) from Swarna. The range of PV explained by each QTL was from 3.0 to $6.8 \%$. Similarly, 3 QTLs were detected for total dry mass on 2 chromosomes ( 2 and 5). The Swarna allele at $q T D M 2.1$ increased the total dry mass by $2.6 \mathrm{~g}$, and the effect of this QTL was over dominance in nature. qTDM2.2 allele was also from Swarna and contributed high PV of 7.7\%. qTDM5.1 from 0. nivara contributed $4.1 \%$ to the total PV.

In $\mathrm{F}_{2}$, only one QTL $q H I 3.1$ was detected on chromosome 3 which was from Swarna and contributed $4.1 \%$ PV. However, in $\mathrm{F}_{3}$, three QTLs were detected on chromosome 1. The trait enhancing allele of $q H I 1.1$ was from 0 . nivara and in the other two QTLs $q H I 1.2$ and $q H I 1.3$ trait enhancing alleles were from Swarna. The PV ranged from 3 (qHI1.1) to 6.1\% (qHI1.2).

QTLs for panicle related traits

In $\mathrm{F}_{3}$, one QTL qPL2.1 for panicle length was detected on chromosome 2 and the trait enhancing allele from IL65 contributed $6.2 \%$ to the PV. Two QTLs were detected for number of secondary branches on two chromosomes (2 and 5). The trait enhancing allele for qNSB2.1 was from O. nivara and explained PV of $2.9 \%$. In the other QTL qNSB5.1 it was from Swarna and explained PV of 5.1\%. Three QTLs for number of filled grains per panicle were detected on chromosome 2, and the trait enhancing QTL alleles in each were derived from 0 . nivara. The QTLs qNFG2.1 and qNFG2.2 were detected at a LOD of 2.9 each, and explained 3.9 and $6.2 \%$ PV and had an additive effect of 6.56 and 8.58 grains respectively (Table S11, Online Resource 2). The other QTL qNFG2.3 explained 5.8\% PV with an additive effect of 5.64. qGNP2.1 for total grain number per panicle explained 3.2\% PV and qPWT3.1 for panicle weight explained $3.4 \%$ PV both with trait enhancing allele contributed by 0 . nivara.

Major effect QTL alleles

Only two major effect QTL alleles were detected in $\mathrm{F}_{2}$ and $\mathrm{F}_{3}$ populations (Fig. 2b). One QTL qDTF1.2 (RM8094-RM5638) for days to flowering was detected at LOD 6.7 in $\mathrm{F}_{2}$. The trait enhancing QTL allele was from Swarna and explained 13.5\% PV. The other adjacent QTL qDTF1.3 (RM5638-RM9) for days to flowering was detected at the highest LOD of 7.4 and explained 9.1\% PV. Together these two QTLs explained 22.6\% of PV. In $\mathrm{F}_{3}$, one major effect QTL qFLA1.1 (RM8094-RM5638) was detected for flag leaf area and explained PV of 21\%. The trait enhancing QTL allele was from 0 . nivara and had an additive effect of $2.74 \mathrm{~cm}^{2}$. The adjacent QTL $q F L A 1.2$ was also detected at a high LOD of 7.3 with a PV of $8 \%$ and together these two QTLs explained $29 \%$ of PV.

Co-localization of QTLs

The QTLs identified for different traits often clustered in the same chromosomal regions. Two chromosomal regions with three or more QTLs for different morphological, physiological and yield related traits were identified on two chromosomes. On chromosome 1 two contiguous QTL clusters (RM8094-RM5638 and RM5638-RM9) were detected for seven traits and three contiguous QTL clusters on chromosome 2 (RM207RM3774, RM3774-RM13260 and RM13260-RM5460) for nine traits (Fig. 2c).

The comparison of QTLs on chromosome 2 revealed that all the yield related traits whose loci are on chromosome 2 are also highly correlated. For example, number of tillers, number of productive tillers, yield per plant, biomass and total dry mass were significantly correlated and also co-localized in the region between RM207 and RM3774 in $\mathrm{F}_{2}$. Likewise, plant height, panicle length and grain number per panicle are highly correlated and their QTLs co-localized in the region between RM13260 and RM5460 in F 3 (Table S12, Online Resource 2).

Epistatic interactions for flag leaf size and yield related traits

Epistatic interactions (digenic) between the marker loci for single environment detected 167 interactions for all 10 traits except for DTF and SPAD in $\mathrm{F}_{2}$. Two significant digenic interactions were detected for FLL between the marker loci on chromosome 4 and chromosome 6 . Thirteen interactions were detected for FLW and eighteen interactions were detected for FLA on chromosome seven and 11 simultaneously. Chromosome 11 showed high number of (5) interactions for FLA with the marker loci on other chromosomes and showed high LOD of 8.9. SPAD, PH, NT, NPT, BM, TDM and DTF showed lowest interactions and YLDP and HI showed highest epistatic interactions across all the

Page $10 / 23$ 
chromosomes (Fig. S8, Online Resource 1). Interestingly, the loci on chromosome 2 interacted with QTLs on different linkage groups. In $F_{3}, 496$ significant epistatic interactions were detected for all 21 traits except for SPAD. Among these, FLL showed one epistatic interaction between the marker loci on chromosome 2 (RM5404-RM12924, 30cM) and chromosome 11 (RM332-RM209, 25cM) contributing 7.4\% of PV at a LOD of 5.9. Five significant interactions were detected for FLW on chromosome 1, 2, 4 and 6. Similarly, FLA showed three digenic interactions on chromosome 1, 6 and 12. Of these, the interaction between the marker loci on chromosome 1 (RM1-RM579, 20cM and RM8094-RM5638, 95cM) contributes high percentage of PV 8.6 with a LOD of 5.1 (Fig. 3). YLDP, BM, TDM, HI, NFG and GNP showed lowest interactions and DFF showed highest interactions followed by PL, NPB, PH, SF and TGW across all chromosomes (Fig. S9, Online Resource 1).

Distribution, number and length of substituted chromosome segments in CSSL

In all, 55 CSSLs in $\mathrm{F}_{2}$ carried 436 homozygous chromosome segments from IL65 (O. nivara) substituted in place of Swarna. On an average each CSSL contained eight 0 . nivara segments. The substituted chromosome segments in the CSSLs covered most of the 12 chromosomes, except for a small region on chromosome 10 (proximal region of long arm of chromosome 10) (Fig. 4). Maximum number of (14) chromosome segment substitutions were found in CSSL130 and CSSL217, whereas minimum number (2) of chromosome segment substitutions were found in CSSL92 based on data of 93 SSR markers. In all, highest number of introgressions were found on chromosome 2, and least on chromosome 9 . Among the $55 \mathrm{CSSLs}$ the size of the substituted segment ranged from $0.50 \mathrm{cM}$ (on chromosome 4 of CSSL 398 ) to $39.35 \mathrm{cM}$ (on chromosome 4 of CSSL282) with an average genetic distance of 22cM. Phenotypically, out of 55 CSSLs, 52 were significantly different (higher or lower) from either Swarna or IL65 for at least one of 17 traits. Thirty-three CSSLs had significantly lower trait values and only three CSSLs, CSSL 41 (for SPAD, PH), CSSL 57 (for PH), and CSSL 325 (for NFG, GNP) had significantly higher trait values than Swarna and IL65 (Table S13, Online Resource 2). These elite CSSLs are useful genetic resource for fine mapping.

In silico analysis of candidate genes within the major effect QTL

The physical length of major effect QTL qFLA1.1 for flag leaf area between RM8094-RM5638 (hotspot1-1) is 9Mb and RM5638-RM9 is 3Mb (hotspot1-2) (together 12Mb) on long arm of chromosome 1. It contains 1063 putative candidate genes (hotspot 1-1 contains 801 and hotspot 1-2 contains 262), which maybe involved in improving flag leaf and yield-related traits. Genes already reported for flag leaf size and yieldrelated traits were found in this region. These reported putative candidate genes are listed in Table S14, Online Resource 2.

\section{Discussion}

Flag leaf is the main photosynthetic organ and plays a pivotal role in capturing of light, and energy utilization at grain filling stage. Thus flag leaf area has a direct impact on photosynthesis efficiency and increasing leaf area can help increase yield. Related wild species have the potential to increase flag leaf area. We report here that an Oryza nivara allele of a major effect novel 9Mb QTL qFLA1.1 increases flag leaf area in rice. In the present study two hotspot pleiotropic QTL or QTL clusters were identified each on chromosome 1 and 2. The hotspot 1 (RM8094RM5638-RM9) region on long arm of chromosome 1 is novel and not reported earlier for flag leaf and yield-related traits in rice using wild derived introgression lines. This hotspot 1 region has a cluster of 11 QTLs for 7 traits (flag leaf length, flag leaf width, flag leaf area, SPAD, days to flowering, plant height and harvest index) mapped in $\mathrm{F}_{2}$ and $\mathrm{F}_{3}$. In $\mathrm{F}_{2}$, one QTL qDTF1.2 for days to flowering was located between RM8094 and RM5638 (hotspot 1-1) on chromosome 1 and another QTL qDTF1.3 for days to flowering was located adjacently between RM5638 and RM9 (hotspot 1-2). The trait-enhancing QTL allele was from Swarna in both.

Heading date and days to fifty percent flowering are key determinants of rice maturity and yield and influenced by many environmental factors such as day length, temperature, light intensity and nutrients. In the present study ten QTLs were identified for days to flowering in $F_{2}$, three QTLs were located on chromosome 1, one on chromosome 3, two each on chromosome 6, 10 and 12. Swamy et al. (2011) identified 6 QTLs for days to heading and six QTLs for days to $50 \%$ flowering in $\mathrm{BC}_{2} \mathrm{~F}_{2}$ population derived from Swarna/ O. nivara (IRGC81848) and showed three major effect QTLs qDTH11.1 (PV = 20\%) and qDFF6.1 (PV = 22\%) and qDFF9.1 (PV = 22\%) for days to heading. However, the QTL qDTF3.1 identified on chromosome 3 in the present study is between RM3265 and RM231 and located 1.4Mb upstream of qDTH3.1. Similarly in present study RM204 flanking qDTH6.1 was a common marker flanking a major QTL for days to heading on chromosome 6 reported previously and the trait enhancing allele was from Swarna (Swamy et al. 2011). But, in present study the trait enhancing allele is from 0 . nivara. This might be as the other flanking marker was not used in previous study. Out of $427 \mathrm{~F}_{2}$ lines used in this study only 21 lines had 0 . nivara alleles at both the flanking marker positions of hotspot 1. These can be used in marker aided selection to develop Swarna improved for several traits. About 618 QTLs have been shown to control heading date in rice (www.gramene.org accessed on 6th March 2019).

In $\mathrm{F}_{2}, 16$ marker loci on five chromosomes (1, 3, 6, 8 and 12) were associated with days to flowering. Among these RM5638 and RM9 on chromosome1, RM3265 on chromosome 3 and RM19391 on chromosome 6 showed a significantly $(P<0.001)$ strong association. In $\mathrm{F}_{3}$, two loci RM13260 on chromosome 2 and RM5436 on chromosome 7 showed significant association with days to $50 \%$ flowering but in $\mathrm{F}_{3}$ no QTL was detected for DFF, this might be as $\mathrm{F}_{3}$ families were grown under long day condition in rabi 2014. Interestingly, RM5436 on chromosome 7

Page $11 / 23$ 
was located 77.6Kb upstream to Ghd7, a major QTL reported previously for delayed flowering, increased plant height, grain number per panicle and grain yield under long day duration (Xue et al. 2008; Yan et al. 2011, 2013).

In $\mathrm{F}_{3}$, the only one major effect QTL detected was qFLA1.1 for flag leaf area and located between RM8094 and RM5638 (hotspot1-1) on chromosome 1 with a LOD value of $3, \mathrm{PV}$ of $12.7 \%$, and a high additive effect of $2.45 \mathrm{~cm}^{2}$. There was an adjacent minor QTL $q F L A 1.2 \mathrm{for}$ flag leaf area between RM5638 and RM9 (hotspot1-2) with high LOD of 6.4 and 7\% PV and additive effect of $1.66 \mathrm{~cm}^{2}$. These two QTLs had trait enhancing alleles from 0 . nivara. The leaf morphological and physiological traits were controlled by many QTLs and were influenced by several environmental factors (Zhang et al. 2009; Haritha et al. 2018a).

In present study flag leaf length, width and area are mutually correlated. The correlation between flag leaf size and yield-related traits revealed flag leaf length and area were significantly $(P<0.05)$ correlated with plant height, yield per plant, biomass, total dry mass, panicle length, number of primary branches, number of secondary branches, number of filled grains and grain number per panicle. Earlier studies have shown that increased flag leaf length, leaf width and leaf area contribute to plant height, tiller number (Sonah et al. 2012), days to 50\% flowering (Marathi et al. 2012), pancle length (Rahman et al. 2013), primary branches, secondary branches and thousand-grain weight (Wang et al. 2012), increased spikelet number per panicle (Yue et al. 2006; Yin et al. 2017), above ground biomass Rahman et al. 2013; Eizenga et al. 2016) and yield per plant (Marathi et al. 2012; Zhang et al. 2015).

Wang et al. (2012) identified flag leaf size related QTLs on chromosome 1, 6, 7 and 8 which were co-located with yield related traits - plant height, panicle length, panicle weight, primary branch number and secondary branch number. Interestingly our major effect QTL qFLA1.1 for flag leaf area, is 2.3Mb downstream to their QTLs qFLA1.1. Recent report of Wen et al. (2020) showed a major effect QTLs qTLL1 and qTLLW1 for third leaf length and third leaf width on long arm of chromosome 1. We could not find out the positions of these QTLs because of usage of different markers. Similar study was conducted by Farooq et al. (2010) in $F_{2}$ population derived from IR64 (indica) and its derived introgression lines (from new plant rice) and identified 4 QTLs for flag leaf size. One QTL qLLnpt-1 for leaf length and qFLWnpt-1 for flag leaf width were detected in an $\mathrm{F}_{2}$ population of HKL 69 and HFG 27 respectively. The QTL qLLnpt-1 is $11 \mathrm{Mb}$ downstream to our QTL $q F L L 1.1$ and $q F L W n p t-1$ is on short arm of chromosome 1. The QTLs qFLLnpt-4 controls flag leaf length and qFLWnpt-4 controls flag leaf width on chromosome 4 are colocated. Tian et al. (2014) identified a locus between RM3521 and RM8111 on short arm of chromosome 1 that controls both flag leaf width and grain number per panicle in $\mathrm{F}_{2}$ population derived from HP (indica) and Nipponbare (japonica). The markers associated with hotspot 1 are previously reported as linked to other traits also. RM8094 at hotspot1-1 is one of the most useful and informative marker within Saltol QTL for salt tolerance (Ganie et al. 2016; Chowdhury et al. 2016). RM5638 at hotspot 1-2 is linked to $q b r-1.1$ for brown rice yield, $q$ kl-1.1 for kernel length, $q k w t-1.1$ for kernel weight, qmr-1.1 and for total milled rice (Nelson et al. 2012). But the association of hotspot 1 markers for flag leaf related traits were not reported previously.

The other QTL cluster was hotspot 2 (RM207-RM3774-RM13260-RM5460) that has 11 minor effect QTLs for 9 traits were detected on long arm of chromosome 2. However hotspot 2 - 1 (RM207-RM3774) and hotspot 2-2 (RM3774-RM13260) influences number of tillers, number of productive tillers per plant, yield per plant, biomass and total dry mass, whereas hotspot 2-3 (RM13260-RM5460) influences panicle length, number of secondary branches, number of filled grains and grain number per panicle in $F_{2}$ and $F_{3}$. The QTLs for source related traits were colocated with some sink-related traits (Cui et al. 2003; Zhang et al. 2015; Wang et al. 2020). In our study 5 minor effect QTLs for SPAD, FLL, FLW, $\mathrm{PH}$ and $\mathrm{HI}$ were also co-located in hotspot1 (RM8094-RM5638-RM9) region on chromosome 1. This is a novel hotspot region detected for these traits in present study.

The QTL clusters represent the genes with either pleiotropic effects on many traits or close linkage of different genes in rice (Wang et al. 2012) and wheat (Liu et al. 2018b). Populations derived from crosses between a single wild accession of $O$. rufipogon eg acc IRGC105491 and diverse cultivars identified different QTLs for domestication traits (Xiao et al. 1998; Septiningsih et al. 2003; Thomson et al. 2003; Xie et al. 2006; McCouch et al. 2007). The QTLs $q Y L D 2.1$ flanked by RM207 and RM3774 and $q Y L D P 2.2$ flanked by RM3774 and RM13260 explained 4.4 and $6.9 \% \mathrm{PV}$ respectively in $\mathrm{F}_{2}$. Interestingly these QTLs were co-located within $q Y L D 2.1$ for yield and this is a narrower range than their QTL from population $1\left(\mathrm{BC}_{2} \mathrm{~F}_{2}\right.$ BILs using accession IRGC81848) and population $2\left(\mathrm{BC}_{2} \mathrm{~F}_{2}\right.$ BILs using accession IRGC81832) of Swarna $\times 0$. nivara (Swamy et al. 2014). The QTLs $n f g 2.1$ for number of filled grains per plant, $n s p 2.1$ number of spikelets per plant, $d t m 2.2$ days to maturity, ph2. 1 plant height, qyld2.1 yield per plant and $q b m 2.1$ vegetative biomass have been reported previously from $\mathrm{BC}_{2} \mathrm{~F}_{2}$ population of Swarna x O. nivara IRGC81848 were co-located within hotspot 2 region on chromosome 2 (Swamy et al. 2014). Similarly the QTL qBY2.1 for bulk yield reported by Surapaneni et al. (2017) was at hotspot 2. Indicating the yield enhancing QTL alleles from O. nivara (accession IRGC81848) which were detected in $\mathrm{BC}_{2} \mathrm{~F}_{2}$ (which included IL65s as one of the lines among $250 \mathrm{BC}_{2} \mathrm{~F}_{2}$ lines) were validated in a secondary mapping population [ $\mathrm{F}_{2: 3}$ of IL65 $x$ Swarna] used in this study. Such QTLs appear stable across generations. Similarly Balakrishnan et al. (2020) reported 3 QTL clusters on chromosome 1, 8 and 11 in $\mathrm{BC}_{2} \mathrm{~F}_{8}$ BILs derived from Swarna $x$ O. nivara IRGC81832 that showed pleiotropic effect on 10 QTLs for 7 yield related traits. The QTLs $q B M 1.1$ controlling biomass was collocated with $q P H 1.1$ for plant height and $q T D M 1.1$ for total dry mass on chromosome 1. Interestingly, this QTL cluster was 7.4Mb downstream to our hotspot 1-2 region on chromosome 1.

Page $12 / 23$ 
Hence these are worthy of not only fine mapping and cloning for gene discovery but also may be useful for use in MAS or MAB as we show the effect of alleles from $O$. nivara is consistent across generations and populations.

Flag leaf traits and yield were collocated on chromosome 1 and chromosome 2 in our study (hotspot 1 and hotspot 2 ) and this has been reported previously also. Tang et al. (2018) identified 14 QTLs for flag leaf length and 9 QTLs for flag leaf width in a CSSL population of Zhenshan 97 (indica) and Nipponbare (japonica). Among these, two QTLs ( $q F L 7-2$ and qFW7-2) were detected in the same region near the heading date QTL GHD7.1 and explained 11 and 5.5\% PV. Further, validation of this yield related region which controls flag leaf length, flag leaf width, photosynthetic capacity, flowering time and yield potential is required. 43 QTLs for flag leaf size, shape and yield related traits were identified from 135 RILs derived from 93-11(indica) and cv. Peiai64s (javanica) (PA64s) and a major and novel QTL qFLW7.2, for flag leaf width was identified between INDEL7-2 and INDEL7-3 on chromosome 7. Interestingly $q P Y 7$ for plant yield and $q F L W 7$ were co-located within the same interval region on chromosome 7 (Zhang et al. 2015). Li et al. (1999) identified five QTLs related to flag leaf area on chromosomes 2 , 5, 6, 7 and 9 in $\mathrm{F}_{2}$ population derived from Lemont (japonica) and Teqing (indica). They concluded that leaf area was positively correlated to grain yield, and QTLs influencing flag leaf related traits and grain yield-related traits were mapped to similar genomic regions and showed positive influence on the traits. Thus, in addition to chromosome 1 other chromosomes also have flag leaf area QTLs collocated with yield trait QTLs. Since the QTL on chromosome 1 is a major QTL with increasing effect from the related wild species 0 . nivara and identified in a largely Swarna background, it is reasonable to assume that once fine mapped and cloned it holds promise for use in marker assisted transfer. It may be noted that NAL 1 for narrow leaf has recently been cloned (Qi et al. 2008).

The 0 . nivara derived CSSLs were reported in $\mathrm{BC}_{2} \mathrm{~F}_{8}$ but they were not screened for leaf traits (Surapaneni et al. 2017, Balakrishnan et al. 2020). Any CSSL with significantly higher or lower flag leaf area than Swarna can be used for narrowing the 9Mb QTL further. CSSLs are excellent genetic resource to understand the genetic architecture of complex traits. In present study 55 CSSLs were identified from Swarna and 0 . nivara derived IL65 population using 93 SSRs. Among these three CSSLs, CSSL 41 showed significantly higher SPAD, plant height, CSSL 57 for plant height, and CSSL 325 for number of filled grains and grain number per panicle were significantly higher than Swarna and IL65. These elite CSSLs are useful genetic resource for fine mapping. Balakrishnan et al. (2018) reviewed the importance of CSSLs in several crops. Surapaneni et al. (2017) identified 74 CSSLs from Swarna x O. nivara IRGC81848 population using 111SSRs. Of these IL142S showed significantly higher biomass, IL220S and IL166-23-1S showed significantly higher panicle weight than Swarna x O. nivara IRGC81848 population. Likewise, Balakrishnan et al. (2020) identified 70CSSLs from backcross population of Swarna x O. nivara IRGC81832 using $140 S S R s .0 f$ these NK61 showed significantly higher per day productivity and yield per plant than Swarna. Similarly, Furuta et al. (2016) reported 26 NSLs (chromosome segment substitution lines) derived from Koshihikari x 0 . nivara. Of these 5NSLs showed significantly higher or lower culm/ panicle length, number of tillers, grain number per panicle, 100-grain weight and grain length than Koshihikari.

In present study a novel chromosomal regions was identified for SPAD ( $q S P A D 1.2, q S P A D 1.3)$, flag leaf length ( $q F L L 1.1, q F L L 1.2)$, flag leaf width ( $q F L W 1.2, q F L W 1.3)$, flag leaf area ( $q F L A 1.1, q F L A 1.2)$, plant height ( $q P H 1.1, q P H 1.2)$, days to flowering ( $q D T F 1.2, q D T F 1.3)$ and harvest index ( $q H I 1.2, q H I 1.3)$. All these QTLs were collocated within the 12Mb region between the intervals of RM8094-RM5638 (9Mb) and RM5638RM9 (3Mb). This region contains 1063 genes. Of these, there were six reported candidate genes three in each region (1-1 and 1-2) of hotspot1 and known to control leaf blade area (Alqudah et al. 2018), leaf senescence (Jain et al. 2007; Chen et al. 2013), days to flowering (Shuai et al. 2002), sucrose transport (Toyofuku et al. 2000), photosynthesis (Morinaka et al. 2006), plant architecture (Huang et al. 2018), plant height (Matusmoto et al. 2016), internode elongation (Panda et al. 2018), grain size (Huang et al. 2008), grain filling (Wu et al. 2008), and grain yield (Zhang et al. 2014). Interestingly the semi dwarfing gene sd-1 (Similar to GA C20oxidase2) is located 15Mb downstream of hotspot 1-1 region on the long arm of chromosome 1. Spielmeyer et al. (2002) reported that $s d-1$ gene is involved in shortening of culm length and improves lodging resistance with greater harvest index in rice. Wang et al. (2017) reported a gene IPA1 (ideal plant architecture interacting protein 1) RING-finger E3 ligase, that interacts with the gene IPA1. This is located within hotspot 1-1 region on chromosome 1 of our study, where several minor QTLs for flag leaf and yield-related traits were co-located. Wang et al. (2011) fine mapped the major effect QTL qFL 1 that controls flag leaf size to a candidate gene OSFTL1. OSFTL 1 showed pleiotropic effect on flag leaf size, heading date and other yield related traits. It is interesting to note that our QTL qFLA1.1 for flag leaf area identified in $\mathrm{F}_{3}$ is the same region where the major QTL qDTF1.2 for days to flowering was identified in $\mathrm{F}_{2}$ of our study. Thus, the QTLs in hotspot 1 region are high priority regions and it is worthy for further fine mapping to identify the causal genes.

\section{Conclusion}

The QTLs influencing flag leaf size related traits and several grain yield related traits were mapped to same genomic regions and showed positive influence on the traits. Therefore it is possible to improve grain yield by genetic improvement of flag leaf length, flag leaf width and flag leaf area with the aid of molecular markers. The major effect QTL qFLA1.1 for flag leaf area in hotspot 1 region is novel and in 9Mb region QTL cluster for correlated yield related traits. It is worthy of fine mapping and functional validation of markers for use in marker assisted selection for flag leaf size related traits use in MAS. Five ILs showed higher grain yield (g) FLL, FLW, PH, BM and TDM than both parents

Page $13 / 23$ 


\section{Abbreviations}

CSSL Chromosome segment substitution line

FLL Flag leaf length

FLW $\quad$ Flag leaf width

FLA Flag leaf area

IL Introgression line

LOD logarithm of odds

PV Phenotypic variance

PCR Polymerase chain reaction

QTL Quantitative trait locus

RIL Recombinant inbred line

SSR Simple Sequence Repeats

\section{Declarations}

\section{Data availability}

All datasets generated for this study are included in this article and its supplementary files

\section{Code availability}

Not applicable

\section{Acknowledgments}

We thank staff of Department of Genetics, Osmania University, and Director, IIRR for support at all time for completion of PhD thesis of GH.

\section{Funding}

This research and GH was supported by funds from Department of Biotechnology, Government of India (DBT No.

BT/PR13357/AGR/02/695/2009) and (BT/AB/FG -2 (PHII) (IA/2009).

\section{Author information}

\section{Affiliations}

ICAR- Indian Institute of Rice Research, Rajendranagar, Hyderabad 500 030, India

Haritha Guttikonda, Gowthami Chandu, Suchandranath Babu Munnam, Kavitha Beerelli,Divya Balakrishnan \& Sarla Neelamraju

ICAR- Indian Institute of Millets Research, Rajendranagar, Hyderabad, 500 030, India

Madhusudhana Ragimasalawada

\section{Contributions}

NS and GH designed the study. GH developed the mapping populations. GH, ChG and MSB performed the field experiments under the supervision of NS. GH, ChG, MSB and BK phenotyped and genotyped the mapping populations. DB helped in statistical analysis of phenotypic data and CSSLs. RM helped in construction of linkage map and QTL mapping analysis. GH did in-silico analysis of genes within major QTL. $\mathrm{GH}$ and NS analyzed the data and wrote the manuscript. NS and DB reviewed the manuscript. All authors read and approved the final submission. This is part of PhD work of GH submitted to Osmania University, Hyderabad. 
Correspondence to Sarla Neelamraju

\section{Ethics Declarations}

Not applicable

\section{Ethics approval}

Not applicable

\section{Consent to participate}

Not applicable

\section{Consent for publication}

All authors have approved the manuscript for publication.

\section{Conflict of interest}

The authors declare no competing interests

\section{Supplementary information}

All supplementary data generated during this study are included separately as supplementary figures and supplementary tables.

\section{References}

1. Adachi S, Yamamoto T, Nakae T, Yamashita M, Uchida M, Karimata R, Ichihara N, Soda K, Ochiai T, Ao R, Otsuka C (2019) Genetic architecture of leaf photosynthesis in rice revealed by different types of reciprocal mapping populations. J Exp Bot 70:5131-5144

2. AICRIP (All India Coordinated Rice Improvement Project) (2010) Varietal improvement. Indian Inst Rice Res Annual Progress Rep 1:217220

3. Alqudah AM, Youssef HM, Graner A, Schnurbusch T (2018) Natural variation and genetic make-up of leaf blade area in spring barley. Theor Appl Genet 131:873-886

4. Balakrishnan D, Surapaneni M, Mesapogu S, Neelamraju S (2018) Development and use of chromosome segment substitution lines as a genetic resource for crop improvement. Theor Appl Genet 1:1-25

5. Balakrishnan D, Surapaneni M, Yadavalli VR, Addanki KR, Mesapogu S, Beerelli K, Neelamraju S (2020) Detecting CSSLs and yield QTLs with additive, epistatic and QTL× environment interaction effects from Oryza sativax O. nivara IRGC81832 cross. Sci Rep 10:1-7

6. Cai J, Zhang M, Guo LB, Li XM, Bao JS, Ma LY (2015) QTLs for rice flag leaf traits in doubled haploid populations in different environments. Genet Mol Res 14:6786-6795

7. Chang TG, Zhao H, Wang N, Song QF, Xiao Y, Qu M, Zhu XG (2019) A three-dimensional canopy photosynthesis model in rice with a complete description of the canopy architecture, leaf physiology, and mechanical properties. J Exp Bot 70:2479-2490

8. Chen W, Sheng Z, Cai Y, Li Q, Wei X, Xie L, Jiao G, Shao G, Tang S, Wang J, Hu P (2019) Rice morphogenesis and chlorophyll accumulation is regulated by the protein encoded by NRL3 and its interaction with NAL9. Front. Plant Sci 10:175. https://. doi

9. Chen Y, Xu Y, Luo W, Li W, Chen N, Zhang D, Chong K (2013) The F-box protein OsFBK12 targets OsSAMS1 for degradation and affects pleiotropic phenotypes, including leaf senescence, in rice. Plant Physiol 163:1673-1685

10. Chowdhury AD, Haritha G, Sunitha T, Krishnamurthy SL, Divya B, Padmavathi G, Ram T, Sarla N (2016) Haplotyping of rice genotypes using SSR associated with salt tolerance. Rice Sci 23:317-325

11. Churchill GA, Doerge RW (1994) Empirical threshold values for quantitative trait mapping. Genetics 138:963-971

12. Cui K, Peng S, Xing Y, Yu S, Xu C, Zhang Q (2003) Molecular dissection of the genetic relationships of source, sink and transport tissue with yield traits in rice. Theor Appl Genet 106:649-658

13. Dai LP, Lu XL, Zou WW, Wang CJ, Shen L, Hu J, Zhang GH, Ren DY, Chen G, Zhang Q, Xue DW (2020) Mapping of QTLs for source and sink associated traits under elevated $\mathrm{CO}_{2}$ in rice (Oryza sativa L.). Plant Growth Regul 90:359-367

14. Ding X, Li X, Xiong L (2011) Evaluation of near-isogenic lines for drought resistance QTL and fine mapping of a locus affecting flag leaf width, spikelet number, and root volume in rice. Theor Appl Genet 123:815-826 
15. Eizenga GC, Neves PC, Bryant RJ, Agrama HA, Mackill DJ (2016) Evaluation of a M-202 x Oryza nivara advanced backcross mapping population for seedling vigor, yield components and quality. Euphytica 208:157-171

16. Fan G, Dong Y, Wang C, Wan J, Xie H, Xu C, Zhu J, Cai Q (2007) Analysis of QTLs for flag-leaf shape and its response to elevated CO ${ }_{2}$ in rice. Rice Sci 14:7-12

17. Farooq M, Tagle AG, Santos RE, Ebron LA, Fujita D, Kobayashi N (2010) Quantitative trait loci mapping for leaf length and leaf width in rice cv. IR64 derived lines. J Integr Plant Biol 52:578-584

18. Fu X, Xu J, Zhou M, Chen M, Shen L, Li T, Zhu Y, Wang J, Hu J, Zhu L, Gao Z, Dong G, Guo L, Ren D, Chen G, Lin J, Qian Q, Zhang G (2019) Enhanced expression of QTL qLL9/DEP1 facilitates the improvement of leaf morphology and grain yield in rice. Int J Mol Sci 20:866. https://doi.org/10.3390/ijms20040866

19. Furuta T, Uehara K, Angeles-Shim RB, Shim J, Nagai K, Ashikari M, Takashi T (2016) Development of chromosome segment substitution lines (CSSLs) harbouring Oryza nivara genomic segments in Koshihikari and evaluation of yield related traits. Breed Sci 66:845-850

20. Ganie SA, Borgohain MJ, Kritika K, Talukdar A, Pani DR, Mondal TK (2016) Assessment of genetic diversity of Saltol QTL among the rice (Oryza sativa L.) genotypes. Physiol Mol Biol Plants 22:107-114

21. Govindaraj M, Vetriventhan M, Srinivasan M (2015) Importance of genetic diversity assessment in crop plants and its recent advances: An overview of its analytical perspectives. Gene. Res. Int 2015: 431487. http://dx.doi.org/10.1155/2015/431487

22. Haritha G, Malathi S, Divya B, Swamy BPM, Mangrauthia SK, Sarla N (2018a) The wild Oryza genomes. In: Mondal TK, Henrey RJ (eds) Oryza nivara Sharma et Shastry. Springer International Publishing AG, Switzerland, pp 207-238

23. Haritha G, Sudhakar T, Chandra D, Ram T, Divya B, Sarla N (2016) Informative ISSR markers help identify genetically distinct accessions of Oryza rufipogon in yield improvement. Rice Sci 23:225-241

24. Haritha G, Swamy BPM, Naik ML, Jyothi B, Divya B, Malathi S, Sarla N (2018b) Yield traits and associated marker segregation in elite introgression lines derived from O. sativa x O. nivara. Rice Sci 25:19-31

25. Haritha G, Vishnukiran T, Rao YV, Gowthami Ch, Divya B, Sarla N, Subrahmanyam D (2019) Characterization of Oryza nivara introgression lines: A potential prebreeding resource to improve net photosynthetic rate in elite cultivars of rice. Photosynthetica 57:47-60

26. Haritha G, Vishnukiran T, Yugandhar P, Sarla N, Subrahmanyam D (2017) Introgressions from Oryza rufipogon increase photosynthetic efficiency of KMR3 rice lines. Rice Sci 24:85-96

27. Horton P (2000) Prospects for crop improvement through the genetic manipulation of photosynthesis: Morphological and biochemical aspects of light capture. J Exp Bot 51:475-485

28. Huang X, Liu G, Zhang W (2018) Genome-wide analysis of LBD (Lateral Organ Boundaries Domain) gene family in Brassica rapa. Braz Arch Biol Technol 61:e18180049. https://doi.org/10.1590/1678-4324-2018180049

29. Huang YW, Tsay WS, Chen CC, Lin CW, Huang HJ (2008) Increased expression of the rice C-type cyclin-dependent protein kinase gene, Orysa; CDKC; 1, in response to salt stress. Plant Physiol Bioch 46:71-81

30. Isidro J, Knox R, Clarke F, Singh A, DePauw R, Clarke J, Somers D (2012) Quantitative genetic analysis and mapping of leaf angle in durum wheat. Planta 236:1713-1723

31. Jansen RC, Stam P (1994) High resolution of quantitative traits into multiple loci via interval mapping. Genetics 136:1447-1455

32. Jain M, Nijhawan A, Arora R, Agarwal P, Ray S, Sharma P, Kapoor S, Tyagi AK, Khurana JP (2007) F-box proteins in rice. Genome-wide analysis, classification, temporal and spatial gene expression during panicle and seed development, and regulation by light and abiotic stress. Plant Physiol 143:1467-1483

33. Jiang S, Zhang X, Wang J, Chen W, Xu Z (2010) Fine mapping of the quantitative trait locus $q F L L 9$ controlling flag leaf length in rice. Euphytica 176:341-347

34. Jing P, Wang D, Zhu C, Chen J (2016) Plant physiological, morphological and yield-related responses to night temperature changes across different species and plant functional types. Front Plant Sci 7:1774. https://doi.org/10.3389/fpls.2016.01774

35. Johanson HW, Robinson HF, Comstock RE (1955) Genotypic and genotypic correlations in soybean and their implications in selection. Agron J 47:477-483

36. Kim JS, Klein PE, Klein RR, Price HJ, Mullet JE, Stelly DM (2005) Molecular cytogenetic maps of sorghum linkage groups 2 and 8 . Genetics 169:955-965

37. Kobayashi S, Fukuta Y, Morita S, Sato T, Osaki M, Khush GS (2003) Quantitative trait loci affecting flag leaf development in rice (Oryza sativa L.). Breed Sci 53:255-262

38. Kozuka T, Horiguchi G, Kim GT, Ohgishi M, Sakai T, Tsukaya H (2005) The different growth responses of the Arabidopsis thaliana leaf blade and the petiole during shade avoidance are regulated by photoreceptors and sugar. Plant Cell Physiol 46:213-223

39. Lander ES, Botstein D (1989) Mapping Mendelian factors underlying quantitative traits using RFLP linkage maps. Genetics 121:185-199 
40. Li ZK, Paterson AH, Pinson SRM, Stansel JW (1999) RFLP facilitated analysis of tiller and leaf angles in rice (Oryza sativa L.). Euphytica 109:7984

41. Liu K, Xu H, Liu G, Guan P, Zhou X, Peng H, Yao Y, Ni Z, Sun Q, Du J (2018a) QTL mapping of flag leaf-related traits in wheat (Triticum aestivum L.). Theor Appl Genet 131:839-849

42. Liu L, Sun G, Ren X, Li C, Sun D (2015) Identification of QTL underlying physiological and morphological traits of flag leaf in barley. BMC Genet 16:29. https://doi.org/10.1186/s12863-015-0187-y

43. Liu Y, Tao Y, Wang Z, Guo Q, Wu F, Yang X, Deng M, Ma J, Chen G, Wei Y, Zheng Y (2018b) Identification of QTL for flag leaf length in common wheat and their pleiotropic effects. Mol Breed 38:11. https://doi.org/10.1007/s11032-017-0766-X

44. Makino A (2011) Photosynthesis, grain yield, and nitrogen utilization in rice and wheat. Plant Physiol 155:125-129

45. Marathi B, Guleria S, Mohapatra T, Parsad R, Mariappan N, KurungaraVK, Atwal SS, Prabhu KV, Singh NK, Singh AK (2012) QTL analysis of novel genomic regions associated with yield and yield related traits in new plant type based recombinant inbred lines of rice (Oryza sativa L.). BMC Plant Biol 12:137. https://doi.org/10.1186/1471-2229-12-137

46. Matusmoto T, Yamada K, Yoshizawa Y, Oh K (2016) Comparison of effect of brassinosteroid and gibberellin biosynthesis inhibitors on growth of rice seedlings. Rice Sci 23:51-55

47. McCouch SR, Sweeney M, Li J, Jiang H, Thomson M, Septiningsih E, Edwards J, Moncada P, Xiao J, Garris A, Tai T, Martinez C, Tohme J, Sugiono M, McClung A, Yuan LP, Ahn SN (2007) Through the genetic bottleneck: O. rufipogon as a source of trait-enhancing alleles for O. sativa. Euphytica 154:317-339

48. McCouch SR, Teytelman L, Xu Y, Lobos KB, Clare K, Walton M, Fu B, Maghirang R, Li Z, Xing Y, Zhang Q (2002) Development and mapping of 2240 new SSR markers for rice (Oryza sativa L.). DNA Res 9:199-207

49. Meng L, Li H, Zhang L, Wang J (2015) QTL IciMapping: Integrated software for genetic linkage map construction and quantitative trait locus mapping in bi parental populations. Crop J 3:269-283

50. Morinaka Y, Sakamoto T, Inukai Y, Agetsuma M, Kitano H, Ashikari M, Matsuoka M (2006) Morphological alteration caused by brassinosteroid insensitivity increases the biomass and grain production of rice. Plant Physiol 141:924-931

51. Nelson JC, Jodari F, Roughton Al, Mckenzie KM, Mcclung AM, Fjellstrom RG, Scheffler BE (2012) QTL mapping for milling quality in elite western U.S. rice germplasm. Crop Sci 52:242-252

52. Panda D, Mahakhud A, Mohanty B, Mishra SS, Barik J (2018) Genotypic variation of photosynthetic gas exchange and stomatal traits in some traditional rice (Oryza sativa L.) landraces from Koraput, India for crop improvement. Physiol Mol Biol Pla 24:973-983

53. Panigrahy M, Sarla N, Panigrahi KCS (2018) Phenotypic, physiological and biochemical characterization of rice introgression lines and mutants under prolonged shade condition. Res j life sci bioinform pharm chem sci 4:115-130

54. Peng M, Yang G, Zhang J, An B, Li Y (2007) QTL analysis for flag leaf morphological traits in rice (Oryza sativa L.) under different genetic backgrounds. Chin J Rice Sci 21:247-252

55. Peng S, Khush GS, Virk P, Tang Q, Zou Y (2008) Progress in ideotype breeding to increase rice yield potential. Field Crops Res 108:32-38

56. Prasanth VV, Babu MS, Basava RK, Venkata GNT, Mangrauthia SK, Voleti SR, Neelamraju S (2017) Trait and marker associations in Oryza nivara and O. rufipogon derived rice lines under two different heat stress conditions. Front Plant Sci 8:1819. https//. doi

57. Qi J, Qian Q, Bu Q, Li S, Chen Q, Sun J, Liang W, Zhou Y, Chu C, Li X, Ren F (2008) Mutation of the rice Narrow leaf1 gene, which encodes a novel protein, affects vein patterning and polar auxin transport. Plant Physiol 147:1947-1959

58. Qu M, Zheng G, Hamdani S, Essemine J, Song Q, Wang H, Chu C, Sirault X, Zhu XG (2017) Leaf photosynthetic parameters related to biomass accumulation in a global rice diversity survey. Plant Physiol 175:248-258

59. Rahman MA, Haque M, Sikdar B, Islam MA, Matin MN (2013) Correlation analysis of flag leaf with yield in several rice cultivars. J life earth sci 8:49-54

60. Rao YV, Balakrishnan D, Addanki KR, Mesapogu S, Kiran TV, Subrahmanyam D, Neelamraju S, Voleti SR (2018) Characterization of backcross introgression lines derived from Oryza nivara accessions for photosynthesis and yield. Physiol Mol Biol Plants 24:1147-1164

61. Sanchez-Bragado R, Molero G, Reynolds MP, Araus JL (2016) Photosynthetic contribution of the ear to grain filling in wheat: a comparison of different methodologies for evaluation. J Exp Bot 67:2787-2798

62. Sharma SN, Sain RS, Sharma RK (2003) The genetic control of flag leaf length in normal and late sown durum wheat. J Agr Sci-Cambridge 141:323-331

63. Septiningsih EM, Prasetiyono J, Lubis E, Tai TH, Tjubaryat T, Moeljopawiro S, McCouch SR (2003) Identification of quantitative trait loci for yield and yield components in an advanced backcross population derived from the Oryza sativa variety IR64 and the wild relative 0 . rufipogon. Theor Appl Genet 107:1419-1432 
64. Sonah H, Deshmukh RK, Chand S, Srinivasprasad M, Rao GJN, Upreti HC, Singh AK, Singh NK, Sharma TR (2012) Molecular mapping of quantitative trait loci for flag leaf length and other agronomic traits in rice (Oryza sativa). Cereal Res Commun 40:362-372

65. Song Q, Chu C, Parry MA, Zhu XG (2016) Genetics-based dynamic systems model of canopy photosynthesis: the key to improve light and resource use efficiencies for crops. Food Energy Secur 5:18-25

66. Sperotto RA, Ricachenevsky FK, Waldow V, De A, Muller ALH, Dressler VL, Fett JP (2013) Rice grain Fe, Mn and Zn accumulation: How important are flag leaves and seed number? Plant Soil Environ 59:262-266

67. Spielmeyer W, Ellis MH, Chandler PM (2002) Semidwarf (sd-1),"green revolution” rice, contains a defective gibberellin 20-oxidase gene. Proc. Natl. Acad. Sci. U. S. A 99: 9043-9048

68. Stickler FC, Wearden S, Paule AW (1961) Leaf area determination in grain sorghum. Agron J 53:187-188

69. Stuerz S, Asch F (2019) Responses of rice growth to day and night temperature and relative air humidity-dry matter, leaf area, and partitioning. Plants 8:521. https://doi.org/10.3390/plants8110521

70. Surapaneni M, Balakrishnan D, Mesapogu S, Addanki KR, Yadavalli VR, Tripura Venkata VG, Neelamraju S (2017) Identification of major effect QTLs for agronomic traits and CSSLs in rice from Swarna/ Oryza nivara derived backcross inbred lines. Front Plant Sci 8:1027. https://doi.org/10.3389/fpls.2017.01027

71. Swamy BPM (2009) Genome wide mapping of quantitative trait loci (QTLs) for yield and grain quality traits in 0 . sativa cv Swarna $\mathrm{x}$. nivara Backcross population. Dissertation, Osmania University, Hyderabad, India

72. Swamy BPM, Kaladhar K, Ramesha MS, Viraktamath BC, Sarla N (2011) Molecular mapping of QTLs for yield and yield-related traits in Oryza sativa cv Swarna x O. nivara (IRGC81848) backcross population. Rice Sci 18:178-186

73. Swamy BPM, Kaladhar K, Reddy GA, Viraktamath BC, Sarla N (2014) Mapping and introgression of QTL for yield and related traits in two backcross populations derived from Oryza sativa cv. Swarna and two accessions of O. nivara. J Genet 93:643-654

74. Tang X, Gong R, Sun W, Zhang C, Yu S (2018) Genetic dissection and validation of candidate genes for flag leaf size in rice (Oryza sativa L.). Theor Appl Genet 131:801-815

75. Temnykh S, DeClerck G, Lukashova A, Lipovich L, Cartinhour S, McCouch SR (2001) Computational and experimental analysis of microsatellites in rice (Oryza sativa L.): Frequency, length variation, transposon associations, and genetic marker potential

76. GenRes11:1441-1452

77. Teng S, Qian Q, Zeng D, Kunihiro Y, Fujimoto K, Huang D, Zhu L (2004) QTL analysis of leaf photosynthetic rate and related physiological traits in rice (Oryza sativa L.). Euphytica 135:1-7

78. Thomson MJ, Tai TH, McClung AM, Lai XH, Hinga ME, Lobos KB, Xu Y, Martinez CP, McCouch SR (2003) Mapping quantitative trait loci for yield, yield components and morphological traits in an advanced backcross population between Oryza rufipogon and the Oryza sativa cultivar Jefferson. Theor Appl Genet 107:479-493

79. Tian Y, Zhang H, Xu P, Chen X, Liao Y, Han B, Chen X, Fu X, Wu X (2014) Genetic mapping of a QTL controlling leaf width and grain number in rice. Euphytica 202:1-11

80. Toyofuku K, Kasahara M, Yamaguchi J (2000) Characterization and expression of monosaccharide transporters (OsMSTs) in rice. Plant Cell Physiol 41:940-947

81. Tsukaya H (2006) Mechanism of leaf-shape determination. Annu Rev Plant Biol 57:477-496

82. Van Ooijen JW (2006) JoinMap®4, Software for the Calculation of Genetic Linkage Maps in Experimental Populations. Kyazma BV, Wageningen

83. Van Ooijen JW, Voorrips RE (2001) JoinMap 3.0, Software for the calculation of genetic linkage maps. Plant Research International, Wageningen

84. Vinod KK (2011) Kosambi and the genetic mapping function. Resonance 16:540-550

85. Wambugu PW, Furtado A, Waters Daniel LE, Nyamongo DO, Henry RJ (2013) Conservation and utilization of African Oryza genetic resources. Rice 6:29. https://doi.org/10.1186/1939-8433-6-29

86. Wang J, Yu H, Xiong G, Lu Z, Jiao Y, Meng X, Liu G, Chen X, Wang Y, Li J (2017) Tissue-specific ubiquitination by IPA1 INTERACTING PROTEIN1 modulates IPA1 protein levels to regulate plant architecture in rice. Plant Cell 29:697-707

87. Wang Y, Li J (2005) The plant architecture of rice (Oryza sativa). Plant Mol Biol 59:75-84

88. Wang P, Zhou G, Cui K, Li Z, Yu S (2012) Clustered QTL for source leaf size and yield traits in rice (Oryza sativa L.). Mol Breed 29:99-113

89. Wang P, Zhou G, Yu H, Yu S (2011) Fine mapping a major. QTL for flag leaf size and

90. yield-related traits in rice.Theor Appl Genet123:1319-1330

91. Wang YP, Zeng JP, Guo LB, Xing YZ, Xu CG, Mei HW, Ying CS, Luo LJ (2004) QTL and correlation analysis on characters of top three leaves and panicle weight in rice (Oryza sativa L.). Chin J Rice Sci 19:13-20

Page $18 / 23$ 
92. Wang Y, Pang Y, Chen K, Zhai L, Shen C, Wang S, Xu J (2020) Genetic bases of source-, sink-, and yield-related traits revealed by genomewide association study in Xian rice. Crop J 8:119-131

93. Wen Y, Fang Y, Hu P, Tan Y, Wang Y, Hou L, Deng X, Wu H, Zhu L, Zhu L, Chen G (2020) Construction of a high-density genetic map based on SLAF markers and QTL analysis of leaf size in rice. Front Plant Sci 11:1143. https://doi.org/10.3389/fpls.2020.01143

94. Wu CY, Trieu A, Radhakrishnan P, Kwok SF, Harris S, Zhang K, Wang J, Wan J, Zhai H, Takatsuto S, Matsumoto S (2008) Brassinosteroids regulate grain filling in rice. Plant Cell 20:2130-2145

95. Xiao J, Li J, Grandillo S, Ahn SN, Yuan L, Tanksley SD, McCouch SR (1998) Identification of trait-improving quantitative trait loci alleles from a wild rice relative, Oryza rufipogon. Genetics 150:899-909

96. Xie J, Liao H, Wang X, Zhang X, Ni J, Li Y, Tian W, Sang X (2019) DLT/OsGRAS-32, regulating leaf width and thickness by controlling cell number in Oryza sativa. Mol Breed 39:104. https://doi.org/10.1007/s11032-019-1003-6

97. Xie X, Song MHF, Jin SN, Ahn JP, Suh HG, Wang H, McCouch SR (2006) Fine mapping a grain weight quantitative trait loci on rice chromosome 8 using nearly-isogenic lines derived from a cross between Oryza sativa and 0. rufipogon. Theor Appl Genet 113:885-894

98. Xue WY, Xing YZ, Weng XY, Zhao Y, Tang WJ, Wang L, Zhou HJ, Yu SB, Xu CG, Li XH, Zhang QF (2008) Natural variation in Ghd7 is an important regulator of heading date and yield potential in rice. Nat Genet 40:761-767

99. Yan JB, Warburton M, Crouch J (2011) Association mapping for enhancing maize (Zea mays L.) genetic improvement. Crop Sci 51:433449

100. Yan WH, Liu HY, Zhou XC, Li QP, Zhang J, Lu L, Liu TM, Liu HJ, Zhang CJ, Zhang ZY, Shen GJ, Yao W, Chen HX, Yu SB, Xie WB, Xing YZ (2013) Natural variation in Ghd7.1 plays an important role in grain yield and adaptation in rice. Cell Res 23:969-971

101. Yan X, Wang S, Yang B, Zhang W, Cao Y, Shi Y, Sun D, Jing R (2020) QTL mapping for flag leaf-related traits and genetic effect of QFLW-6A on flag leaf width using two related introgression line populations in wheat. PLoS ONE 15:e0229912.

https://doi.org/10.1371/journal.pone.0229912

102. Yang L, Wang J, Lei L, Wang J, Junaid Subhani M, Liu H, Sun J, Zheng H, Zhao H, Zou D (2018b) QTL mapping for heading date, leaf area and chlorophyll content under cold and drought stress in two related recombinant inbred line populations (Japonica rice) and metaanalysis. Plant Breed 137:527-545

103. Yang Y, Zhang M, Xu Q, Feng Y, Yuan X, Yu H, Wang Y, Wei X (2018a) Exploration of genetic selection in rice leaf length and width. Botany 96:249-256

104. Yin C, Li H, Zhao Z, Wang Z, Liu S, Chen L, Liu X, Tian Y, Ma J, Xu L, Zhang D (2017) Genetic dissection of top three leaf traits in rice using progenies from a japonica $x$ indica cross. J. Integr. Plant Biol 59: 866-880

105. Yue B, Xue WY, Luo LJ, Xing YZ (2006) QTL analysis for flag leaf characteristics and their relationships with yield and yield traits in rice. Acta Genet Sin 33:824-832

106. Zhang AH, Xu Q, Zhu XD, Xue HW (2009) SHALLOT-LIKE 1 is a KANADI transcription factor that modulates rice leaf rolling by regulating leaf abaxial cell development. Plant Cell 21:719-735

107. Zhang C, Bai MY, Chong K (2014) Brassinosteroid-mediated regulation of agronomic traits in rice. Plant Cell Rep 33:683-696

108. Zhang B, Ye W, Ren D, Tian P, Peng Y, Gao Y, Ruan B, Wang L, Zhang G, Guo L, Qian Q, Gao Z (2015) Genetic analysis of flag leaf size and candidate genes determination of a major QTL for flag leaf width in rice. Rice 8:2. https://doi.org/10.1186/s12284-014-0039-9

109. Zhao C, Bao Y, Wang X, Yu H, Ding A, Guan C, Cui J, Wu Y, Sun H, Li X, Zhai D (2018a) QTL for flag leaf size and their influence on yieldrelated traits in wheat. Euphytica 214:209. https://doi.org/10.1007/s10681-018-2288-y

110. Zhao X, Fang P, Zhang J, Peng Y (2018b) QTL mapping for six ear leaf architecture traits under water-stressed and well-watered conditions in maize (Zea mays L.). Plant Breed 137:60-72

111. Zheng H, Wang X, Li Y, Huang G, Tang Q, Tang J (2018) Contributions of photosynthetic organs to the seed yield of hybrid rice: the effects of gibberellin application examined by carbon isotope technology. Seed Sci Technol 46:533-546

112. Zheng KL, Subudhi PK, Domingo J, Magpantay G, Huang N (1995) Rapid DNA isolation for marker assisted selection in rice breeding. Rice Genet Newsl 12:255-258

\section{Table}

Table 3 is only available as a download in the Supplemental Files section.

\section{Figures}



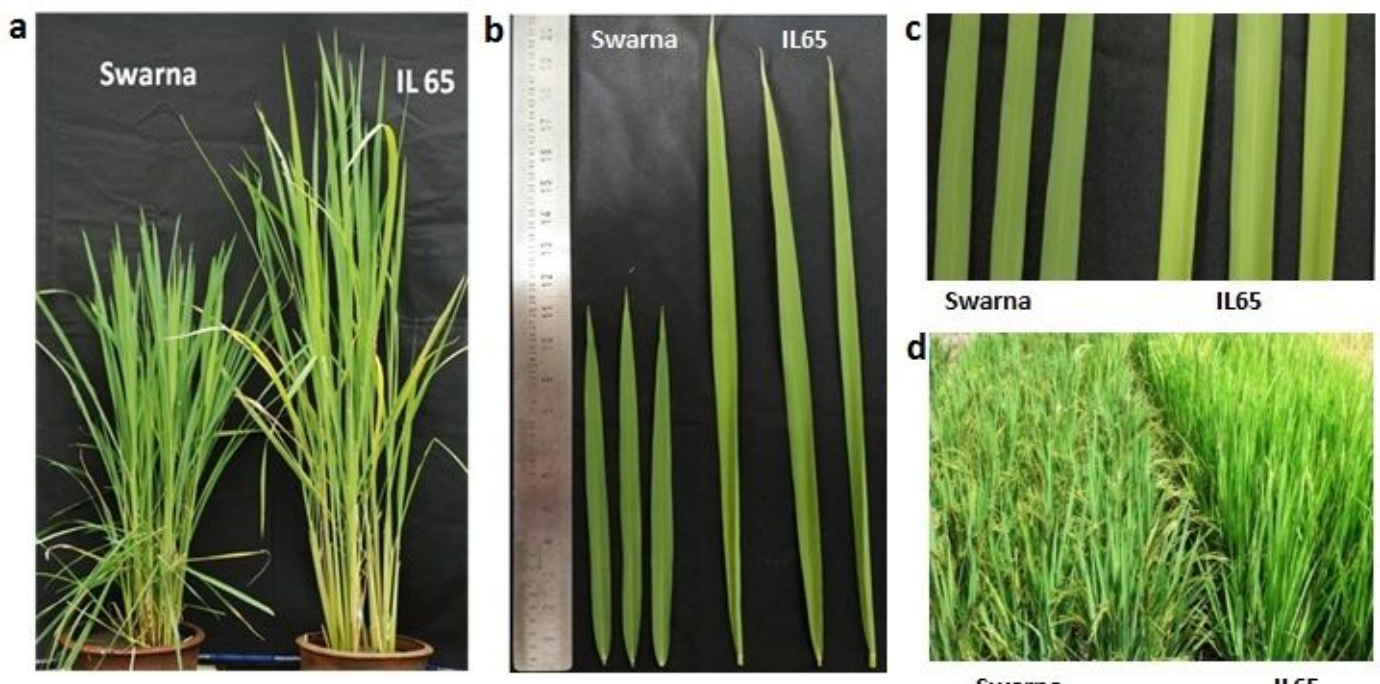

Swarna

IL65

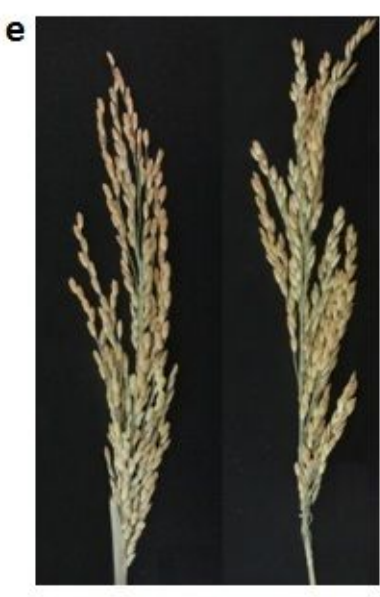

Swarna

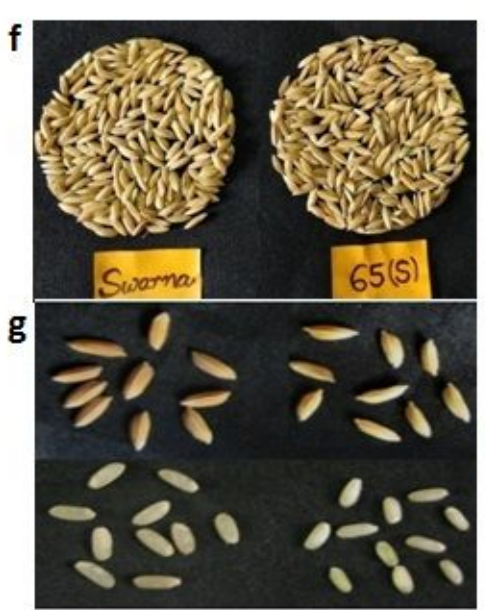

Swarna

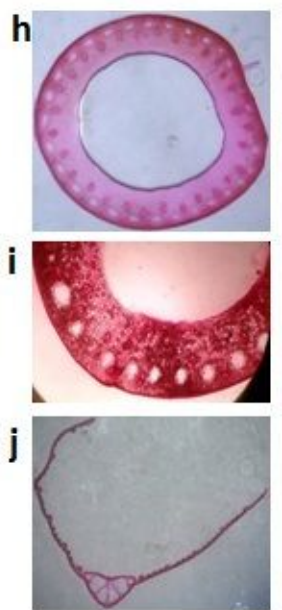

Swarna
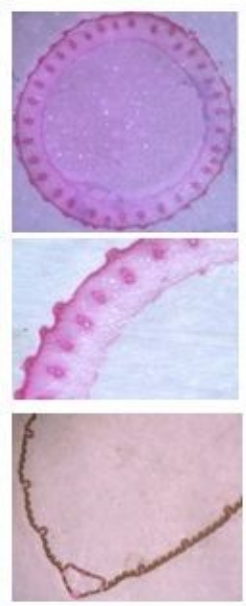

IL65

Figure 1

Morphological and anatomical differences between Swarna and IL65. a plant height. b leaf length. c leaf width. $\mathbf{d}$ flowering duration. e panicle exsertion and spikelet number. $\mathbf{f}$ seeds. $\mathbf{g}$ de hulled rice. $\mathbf{h}$ transverse section of second basal internodes showing 30 vascular bundles in Swarna (left) and 34 in IL65 (right). i enlarged cross section of culm showing presence of large air spaces below epidermis only in Swarna absence in IL65. j hand-cut and cleared transverse section of Swarna and IL65 rice flag leaf at flowering stage, showing the filaments of cells in midrib of Swarna only. 

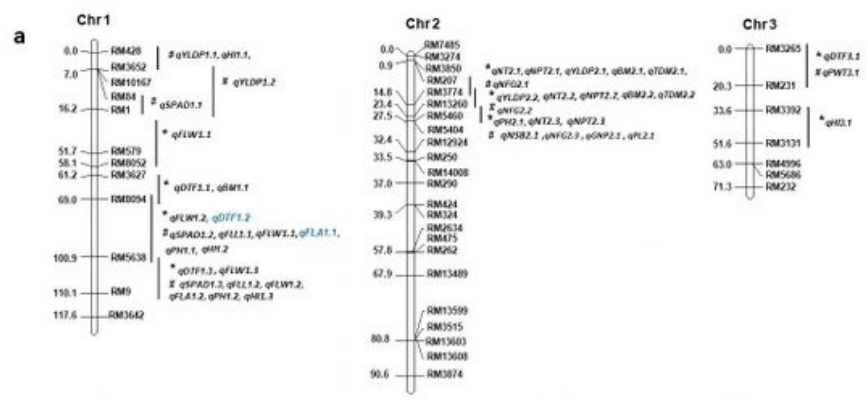

b
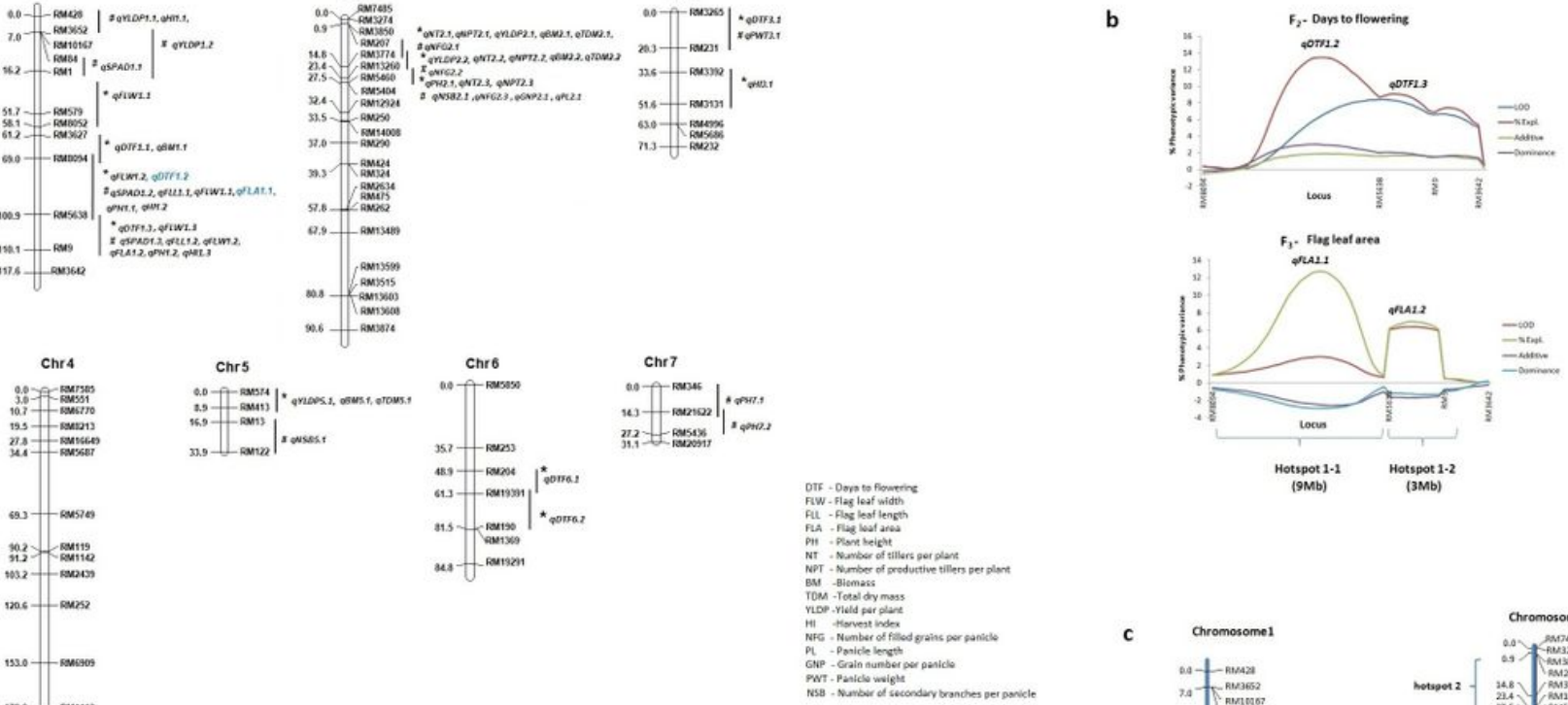

nas
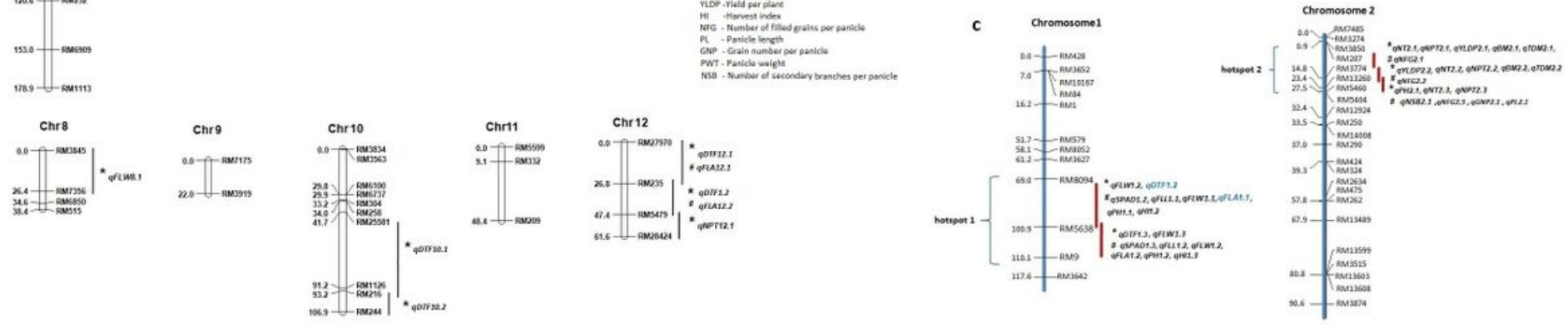

\section{Figure 2}

a Chromosome-wise arrangement of QTLs from $\mathrm{F}_{2}$ and $\mathrm{F}_{3}$ populations. $\mathbf{b}$ major QTLs ( $\left.q D T F 1.1\right)$ identified for days to flowering in $\mathrm{F}_{2}$ and ( $q F L$ A1.1) for flag leaf area in $\mathrm{F}_{3}$ population. c co-localization of QTLs for different traits on chromosome1 and 2. Chr denotes chromosome, *denotes QTLs from $\mathrm{F}_{2}$, \# denotes QTLs from $\mathrm{F}_{3}$. 

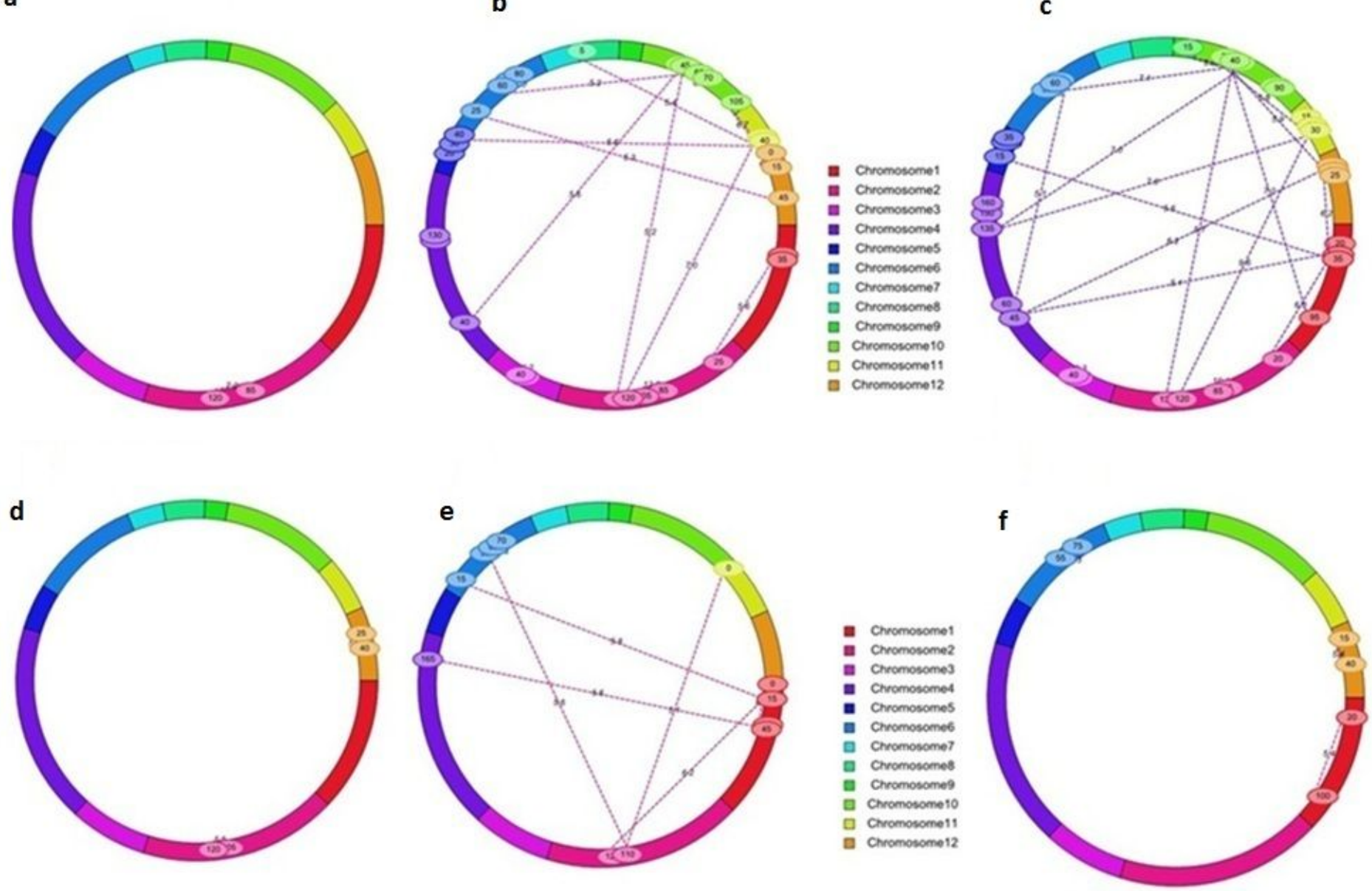

Figure 3

Cyclic representation of epistatic QTLs. a $F_{2}$-flag leaf length. $\mathbf{b} \mathrm{F}_{2}$-flag leaf width. $\mathbf{c} \mathrm{F}_{2}$ - flag leaf area. $\mathbf{d} \mathrm{F}_{3}$-flag leaf length. e $\mathrm{F}_{3}$-flag leaf width. $\mathbf{f}$ $\mathrm{F}_{3}$-flag leaf area

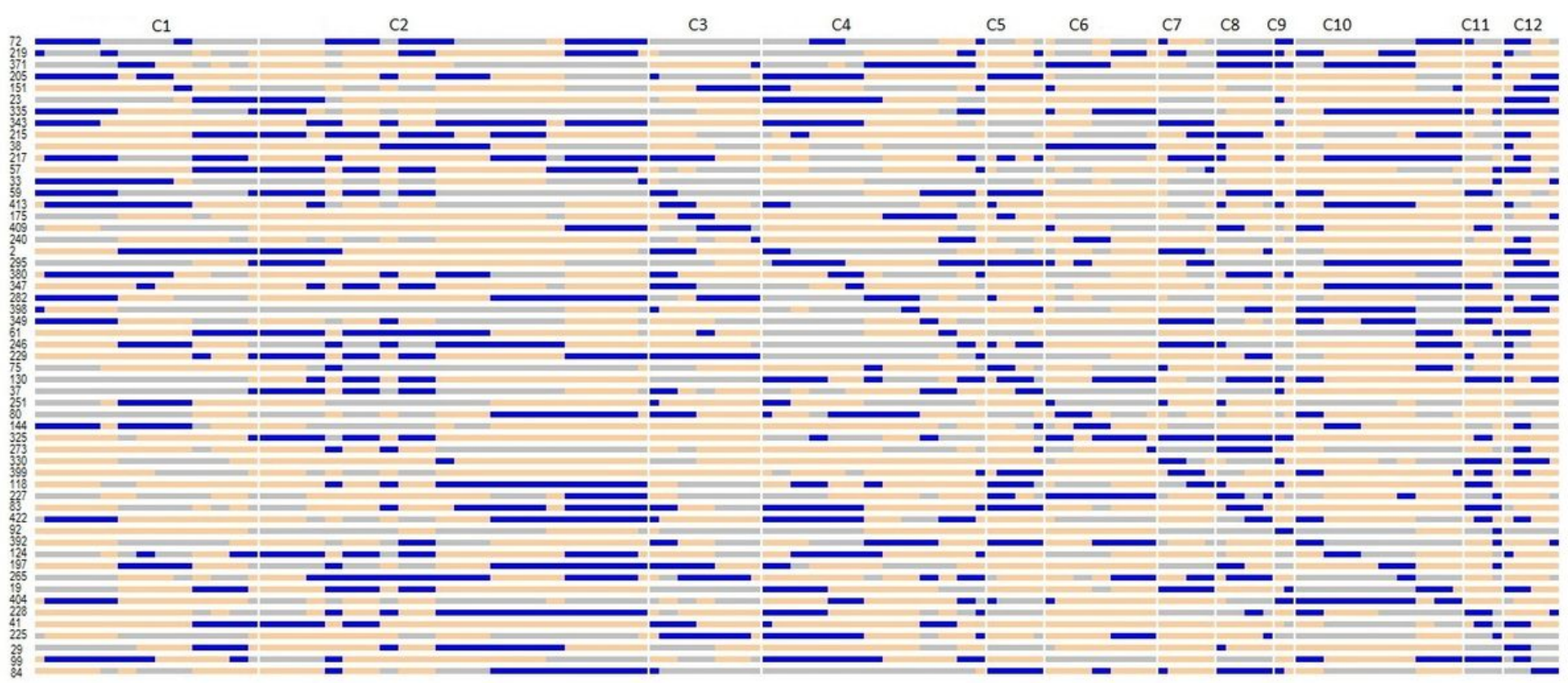

Figure 4 
Graphical representation of genotypes of 55 CSSLs identified based on 93 SSR markers. Grey bars represent the background region homozygous for Swarna alleles, blue bars represent homozygous segments from $\mathrm{O}$. nivara and orange bar represent heterozygous segments. $\mathrm{C}$ refers to chromosome numbers

\section{Supplementary Files}

This is a list of supplementary files associated with this preprint. Click to download.

- Table3.docx 